\title{
Performance of CMIP3 and CMIP5 GCMs to Simulate Observed Rainfall Characteristics over the Western Himalayan Region ${ }^{\circ}$
}

\author{
JiTENDRA KUMAR MEHER AND LALU DAS \\ Department of Agricultural Meteorology and Physics, Bidhan Chandra Krishi Viswavidyalaya, Mohanpur, \\ Nadia, West Bengal, India \\ JAVED AKHTER \\ Department of Physics, Jadavpur University, Kolkata, India
}

Rasmus E. Benestad And AbDelkader Mezghani

Norwegian Meteorological Institute, Oslo, Norway

(Manuscript received 9 November 2016, in final form 16 June 2017)

\begin{abstract}
The western Himalayan region (WHR) was subject to a significant negative trend in the annual and monsoon rainfall during 1902-2005. Annual and seasonal rainfall change over the WHR of India was estimated using 22 rain gauge station rainfall data from the India Meteorological Department. The performance of 13 global climate models (GCMs) from phase 3 of the Coupled Model Intercomparison Project (CMIP3) and 42 GCMs from CMIP5 was evaluated through multiple analysis: the evaluation of the mean annual cycle, annual cycles of interannual variability, spatial patterns, trends, and signal-to-noise ratio. In general, CMIP5 GCMs were more skillful in terms of simulating the annual cycle of interannual variability compared to CMIP3 GCMs. The CMIP3 GCMs failed to reproduce the observed trend, whereas approximately $50 \%$ of the CMIP5 GCMs reproduced the statistical distribution of short-term $(30 \mathrm{yr})$ trend estimates than for the longerterm (99 yr) trends from CMIP5 GCMs. GCMs from both CMIP3 and CMIP5 were able to simulate the spatial distribution of observed rainfall in premonsoon and winter months. Based on performance, each model of CMIP3 and CMIP5 was given an overall rank, which puts the high-resolution version of the MIROC3.2 model [MIROC3.2 (hires)] and MIROC5 at the top in CMIP3 and CMIP5, respectively. Robustness of the ranking was judged through a sensitivity analysis, which indicated that ranks were independent during the process of adding or removing any individual method. It also revealed that trend analysis was not a robust method of judging performances of the models as compared to other methods.
\end{abstract}

\section{Introduction}

Precipitation is an essential input for the Indian agricultural production, water supply, and livelihood. However, accurate quantification of precipitation at the subregional and local scale is considered as a challenging task owing to its erratic behavior and skewed statistics. The amount of global precipitation and its distribution are changing because of human activities leading to the

Supplemental information related to this paper is available at the Journals Online website: https://dx.doi.org/10.1175/ JCLI-D-16-0774.s1.

Corresponding author: Lalu Das, daslalu@yahoo.co.in changing patterns of land use-land cover, reduction of forest cover, and the increase of aerosols in the atmosphere (Basistha et al. 2009).

The study of rainfall change scenario over the Himalayan region is very important as the livelihood of more than 1.27 billion people and the vast biodiversity of India highly depend on meltwater from the Himalayas. However, the accurate estimation of climate change information over this region remains difficult because of its complex topography, sparse data availability, and poor data quality (Singh et al. 1995; Arora et al. 2006; Bhutiyani et al. 2007; Singh et al. 2009; Andermann et al. 2011; Dimri and Dash 2012; Palazzi et al. 2013). Characteristics of observed rainfall distribution over the western Himalayan region (WHR) have been studied 
extensively by many authors (Singh and Kumar 1997; Kripalani et al. 2003; Arora et al. 2006; Basistha et al. 2008, 2009; Bhutiyani et al. 2009; Ray et al. 2011; Dimri and Dash 2012; Negi et al. 2012; Gautam et al. 2013). Similarly the observed rainfall over the Nepal Himalayan region (Higuchi et al. 1982; Shrestha et al. 2000; Barros and Lang 2003; Kansakar et al. 2004; Duncan et al. 2013; Panthi et al. 2015) and eastern Himalayan region (Shrestha and Devkota 2010; Jain et al. 2013) have also been discussed thoroughly.

Over the whole WHR of India, the annual and monsoon rainfall has shown a significant negative trend during 1866-2006 (Bhutiyani et al. 2009). A small part of the WHR (i.e., the Uttarakhand subdivision) has also shown a negative trend in the annual and monsoon rainfall during the last century (Basistha et al. 2009; Singh and Mal 2014). The annual rainfall over some point locations, namely, Handwara, Kulgam, and Srinagar stations of Kashmir valley, also experienced negative trends during 1903-82 (Jain and Kumar 2012). Similarly, a study by Guhathakurta and Rajeevan (2008) reported that the premonsoon rainfall over WHR has shown a positive trend over WHR during 1901-2003. On the other hand, some studies (Bhutiyani et al. 2009; Khan 2001; Shrestha et al. 2000) indicated winter rainfall has shown positive trends in the last century while other studies (Shekhar et al. 2010; Dimri and Dash 2012) reported negative trends in the recent decades over WHR.

GCMs are the most important tools, which provide past and future climate change information at various grid locations over the globe. To this day, output from the GCMs are not adequate to represent the regional-, subregional-, or local-scale climate features properly because of their coarser resolution and inadequate representation of forcing and feedbacks like cloud, convections, evaporation, topography, etc. (Pervez and Henebry 2014; Wilby et al. 1999). Because of these inherent limitations, downscaling of the GCM simulations are essential for impact applications at regional to local scale (Pervez and Henebry 2014; Wilby et al. 1999). In the regional scale, the simulations from the regional climate model (RCM) may be used to assess climate change impact, but on the local scale, instead of using raw GCMs, downscaled GCM output may be used for different impact assessment studies. Otherwise, after evaluating the GCMs' performance, the best-performing GCMs or downscaled information from the GCMs may be used as input in impact models. There are uncertainties associated with future projections of GCMs (Das et al. 2017). The range of possible emission scenarios, internal variability, and intermodel differences are the major source of uncertainties in climate projections (IPCC 2001; Deser et al. 2012; Hingray and Saïd
2014; Akhter et al. 2017). Future trajectories of anthropogenic greenhouse gases (GHGs), aerosol, stratospheric ozone concentrations, land-use change, etc. were included in the emission scenario as external factors that influence the climate system significantly. There is a limited understanding of how GHG will change in the future, hence leading to uncertainty in the choice of emission scenarios. Internal variability is also known as the "natural variability" of the climate system that exists in the absence of "external forcing" (e.g., volcanic eruptions, solar variations, and anthropogenic changes in the composition of the atmosphere) and includes fundamental processes within the atmosphere, the ocean, and the coupled oceanatmosphere system (Deser et al. 2012). Different models may simulate different responses to the same external forcing because of restrictions of model structure and parameterization used to represent geophysical processes.

The Himalayas are a complex topographic region; their climate is strongly influenced by two different modes of climate variability, that is, the South Asian monsoon in the summer [June-September (JJAS)] and the western disturbances in winter to early spring (Hasson et al. 2014; Charles et al. 2016; Das et al. 2017). The combined effect of these variabilities results in difficulties in accurately estimating the precipitation through GCMs. There are very few studies that have used the GCM simulations to quantify the precipitation change over the bigger domains of the Himalayan region apart from using observation data (Palazzi et al. 2013, 2015; Panday et al. 2015; Singh and Goyal 2016; Tiwari et al. 2014). Tiwari et al. (2014) pointed out the varying degree of prediction skill of different GCMs to simulate the winter rainfall over northern India, including Jammu and Kashmir, Himachal Pradesh, and Uttarakhand during the period 1982-2009. The GCMs were neither able to simulate the observed climatology nor able to depict interannual variability of winter rainfall accurately. Some authors have reported that the GCMs were able to capture the mean annual cycle of the observational data coherency but failed to capture its long-term trend (Immerzeel 2008; Palazzi et al. 2013). Palazzi et al. (2015) reported that a majority of the recent generation of CMIP5 GCMs was unable to reproduce the mean annual cycle or the observed trends adequately.

In the CMIP5 project, significant efforts were incorporated to reduce uncertainty in the model simulations, which led to a new generation of global climate models known as Earth system models (Taylor et al. 2012). These models were designed to explicitly represent biogeochemical processes that interact with the physical climate (Flato 2011; Taylor et al. 2012) in addition to a more detailed representation of aerosols and carbon cycles (Taylor et al. 2012; Sperber et al. 2013). It 
also includes models with improved physical parameterization schemes regarding cloud and radiation processes (Dolinar et al. 2015). Therefore, it may be expected CMIP5 will produce more realistic results than CMIP3 as models tend to improve across generations. Das et al. (2012) reported that GCMs have improved their performance across generations starting from the Second Assessment Report (SAR) to the Fourth Assessment Report (AR4) of the IPCC over eastern India. Jourdain et al. (2013) analyzed both CMIP3 and CMIP5 models in reproducing Indo-Australian summer monsoon rainfall and found a reasonably better agreement for CMIP5 models with the observations. Few studies (Palazzi et al. 2013, 2015; Meher et al. 2014; Panday et al. 2015) evaluated the CMIP5 GCM performances over different parts of the WHR and assessed the amount of past and future rainfall change information. The performance of GCMs to simulate the observed climate has been assessed through skill scores and finally assigned a rank to each GCM on the basis of multiassessment criteria (Schaller et al. 2011; Fu et al. 2013). Normally performances of GCMs were evaluated through the comparison of mean seasonal cycles, interannual variability, long-term and short-term climate signal, spatial distribution, signalto-noise ratio, and probability distribution function with observations over different subregional and local scales in different parts of the globe (Miao et al. 2012; Fu et al. 2013; Das et al. 2016a,b). However, similar evaluation of GCMs over the WHR of India is still missing.

The majority of the studies that evaluated the model performance over the Himalayas (Immerzeel 2008; Palazzi et al. 2013, 2015; Panday et al. 2015; Tiwari et al. 2014) used gridded or satellite data as a reference without considering IMD station data. There is no proper information regarding the suitable stations with long-term observational data to be considered as reference stations for assessing the historical rainfall change or any other climate-changerelated impact assessment studies or downscaling experiments over the WHR. Therefore, evaluation of CMIP3 and CMIP5 GCMs with actual station data is quite demanding over relatively sparsely monitored WHR.

Keeping all these background information and research gaps in mind, the present study was carried out to address the following major objectives: 1) to quantify the centennial scale annual and seasonal rainfall change over the WHR and 2) to evaluate the CMIP3 and CMIP5 GCMs and rank them based on their abilities in simulating the observed rainfall through multiple model evaluation methods.

The methods used in this study are described in section 2c. Objective 1 is addressed in section $3 \mathrm{a}$ and sections $3 \mathrm{~b}-\mathrm{d}$ describe the results of the CMIP3 and CMIP5 model evaluation. The major findings of the present study were discussed in section 4 , while section 5 describes the key conclusions.

\section{Materials and methods}

\section{a. Description of the study area}

The study region is a part of the western Himalayan region of India, which lies within $28^{\circ} 42^{\prime}-33^{\circ} 12^{\prime} \mathrm{N}, 75^{\circ} 34^{\prime}-$ $81^{\circ} 05^{\prime} \mathrm{E}$ and comprises the two northern states of India, namely, Himachal Pradesh and Uttarakhand (Fig. 1) (Meher et al. 2016) and some of the major river basins of Beas, Chenab, Ganga, Yamuna, Ravi, and Sutlej. During the winter season, the WHR region receives precipitation in the form of rainfall and snow, which is caused by extratropical storms known as western disturbances (WD), which tend to develop over the Mediterranean Sea and Atlantic Ocean and move eastward (Azadi et al. 2002; Dimri and Ganju 2007; Bhutiyani et al. 2009; Shekhar et al. 2010; Dimri 2012; Dimri et al. 2015). The intraseasonal variability of winter rainfall over the western Himalayan region is also influenced by the northwest propagation of lower-tropospheric air $(850 \mathrm{hPa})$ from the equatorial Indian Ocean (Dimri et al. 2016). During the monsoon season, WHR receives rainfall from the large-scale monsoonal circulation that moves east-west. The amount of precipitation has shown a gradually decreasing trend from east to west mostly as a result of increasing distance from the source region of the Bay of Bengal (Bhatt and Nakamura 2005; Baniya et al. 2013).

\section{b. Data used}

Monthly rainfall of 22 rain gauge stations during the period of 1901-2005 from the India Meteorological Department (IMD) was analyzed. The description of the stations is summarized in Table 1. The IMD daily gridded data at $0.25^{\circ} \times 0.25^{\circ}$ latitude-longitude resolution developed by Pai et al. (2014) was used to fill the missing gaps in the station data. There were 22 reference rain gauge stations that were identified as having continuous data after missing value replacement. Techniques for missing value replacement have been described in section 1 of the supplemental material.

The GCMs used in this study were from both phases 3 and 5 of the Coupled Model Intercomparison Project (CMIP3 and CMIP5) through the data portal of the Royal Netherlands Meteorological Institute (https:// climexp.knmi.nl/selectfield_cmip5.cgi?id=someone@ somewhere for CMIP5 and https://climexp.knmi.nl/ selectfield_co2.cgi?id=someone@somewhere for CMIP3). A total of 13 GCMs from CMIP3 and 42 GCMs from CMIP5 were taken in the present work. The GCMs in its experimental "run 1" (i.e., first ensemble member or r1ilp1) 


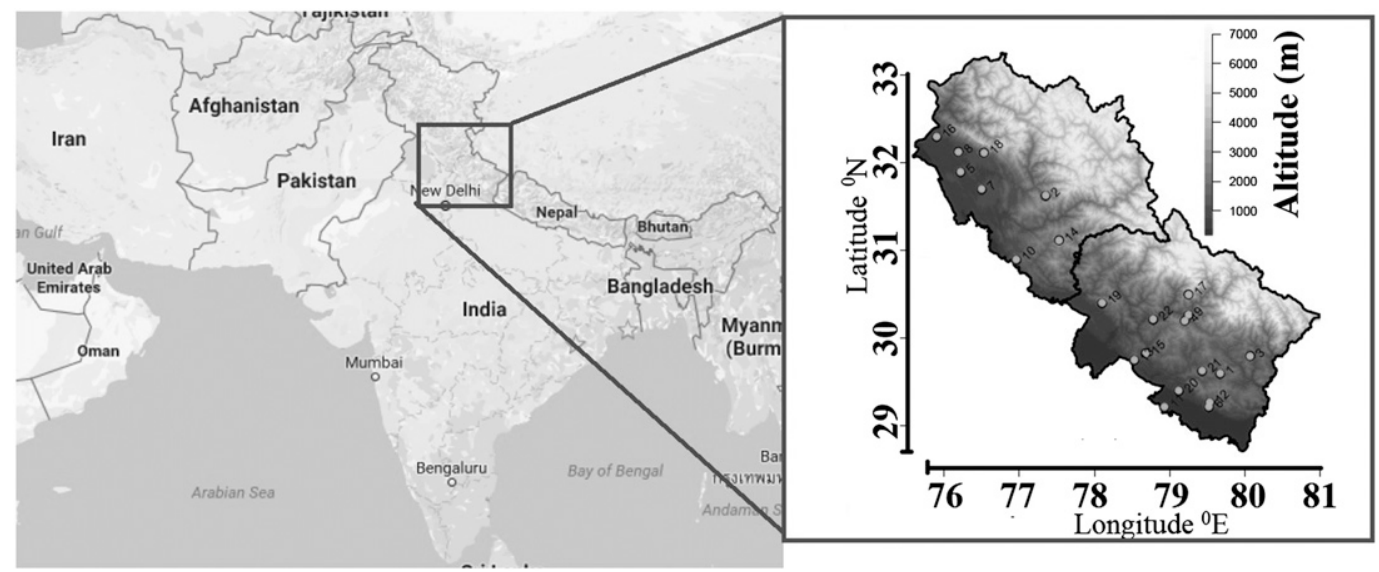

FIG. 1. (left) The location of the study region by highlighted box over the map of India. (right) The distribution of 22 numbers of meteorological stations over the study region.

had monthly precipitation record starting from 1860 to 2100, but for the present study, the time period 1901-2000 was considered for model evaluation. Brief information about the GCMs considered for the study is summarized in Tables S1 and S2 of the supplemental material.

\section{c. Methods of analysis}

The magnitudes of the annual and seasonal precipitation trends were quantified through the Mann-Kendall test
(Mann 1945; Kendall 1957) and Sen's slope estimator (Sen 1968), which are described in detail in section 2 of the supplemental material. The methods of GCM evaluation were described in section $2 \mathrm{c}(1)$. The GCMs under each of the intercomparison projects were ranked based on the values of the scores of different statistical indices (Table 2). Details of these indices are discussed in section 3 of the supplemental material. The sensitivity of individual method was investigated by comparing the score of a single

TABLE 1. Description of 22 rain gauge stations available over WHR along with the seasonal and annual long-term trends (with Sen's slope) during the time period 1902-2005. The mean total annual rainfall $(\mathrm{mm})$ is shown in the last column. Asterisks indicate significance at $10 \%$.

\begin{tabular}{|c|c|c|c|c|c|c|c|}
\hline \multirow[b]{2}{*}{ Station names } & \multicolumn{3}{|c|}{ Station geography } & \multicolumn{3}{|c|}{ Trend and Sen's slope $\left(\mathrm{mm} \mathrm{yr}^{-1}\right)$} & \multirow[b]{2}{*}{ Annual rainfall } \\
\hline & Lat & Lon & Alt (m) & Annual & Monsoon & Winter & \\
\hline Almora & $29.60^{\circ} \mathrm{N}$ & $79.67^{\circ} \mathrm{E}$ & 1676 & -0.76 & -0.41 & -0.06 & 1042.1 \\
\hline Banjar & $31.63^{\circ} \mathrm{N}$ & $77.35^{\circ} \mathrm{E}$ & 1356 & -1.07 & $-1.26^{*}$ & -0.22 & 1050.7 \\
\hline Berinag & $29.80^{\circ} \mathrm{N}$ & $80.07^{\circ} \mathrm{E}$ & 1676 & -0.73 & -0.40 & -0.32 & 1899.7 \\
\hline Bironkhol & $30.20^{\circ} \mathrm{N}$ & $79.20^{\circ} \mathrm{E}$ & 1524 & $-3.03^{*}$ & $-2.08^{*}$ & $-0.58^{*}$ & 1127.0 \\
\hline Dehra Gopipur & $31.90^{\circ} \mathrm{N}$ & $76.22^{\circ} \mathrm{E}$ & 503 & +0.62 & +0.96 & +0.01 & 1363.3 \\
\hline Haldwani & $29.22^{\circ} \mathrm{N}$ & $79.52^{\circ} \mathrm{E}$ & 348 & $-4.84 *$ & $-4.80 *$ & $-0.42 *$ & 1875.9 \\
\hline Hamirpur & $31.70^{\circ} \mathrm{N}$ & $76.50^{\circ} \mathrm{E}$ & 738 & +2.19 & +0.99 & +0.31 & 1415.8 \\
\hline Kangra & $32.13^{\circ} \mathrm{N}$ & $76.19^{\circ} \mathrm{E}$ & 733 & +0.81 & +0.17 & -0.04 & 1964.5 \\
\hline Karnaprayag & $30.27^{\circ} \mathrm{N}$ & $79.25^{\circ} \mathrm{E}$ & 792 & -1.59 & $-2.03^{*}$ & -0.39 & 1387.5 \\
\hline Kasauli & $30.90^{\circ} \mathrm{N}$ & $76.96^{\circ} \mathrm{E}$ & 1927 & -2.10 & -2.15 & -0.34 & 1615.0 \\
\hline Kashipur & $29.22^{\circ} \mathrm{N}$ & $78.93^{\circ} \mathrm{E}$ & 183 & $-4.67 *$ & $-3.95^{*}$ & -0.31 & 1167.9 \\
\hline Kathgodam & $29.27^{\circ} \mathrm{N}$ & $79.53^{\circ} \mathrm{E}$ & 518 & $-4.11^{*}$ & $-4.10^{*}$ & -0.08 & 1945.6 \\
\hline Kotdwara & $29.75^{\circ} \mathrm{N}$ & $78.53^{\circ} \mathrm{E}$ & 399 & $-7.71^{*}$ & $-7.02 *$ & $-0.58^{*}$ & 1522.5 \\
\hline Kotkhai & $31.12^{\circ} \mathrm{N}$ & $77.53^{\circ} \mathrm{E}$ & 1881 & $-2.10^{*}$ & $-1.44^{*}$ & $-0.62 *$ & 927.1 \\
\hline Lansdowne & $29.83^{\circ} \mathrm{N}$ & $78.68^{\circ} \mathrm{E}$ & 1532 & $-6.63^{*}$ & $-5.68^{*}$ & $-0.65^{*}$ & 1897.4 \\
\hline Nurpur & $32.30^{\circ} \mathrm{N}$ & $75.90^{\circ} \mathrm{E}$ & 643 & -0.73 & -1.33 & -0.22 & 1532.9 \\
\hline Okhimath & $30.50^{\circ} \mathrm{N}$ & $79.25^{\circ} \mathrm{E}$ & 1861 & +0.61 & +0.68 & -0.06 & 1992.8 \\
\hline Palampur & $32.12^{\circ} \mathrm{N}$ & $76.53^{\circ} \mathrm{E}$ & 1472 & -3.65 & $-3.29 *$ & -0.71 & 2475.3 \\
\hline Rajpur & $30.40^{\circ} \mathrm{N}$ & $78.10^{\circ} \mathrm{E}$ & 732 & $-11.38^{*}$ & $-10.50 *$ & $-0.54^{*}$ & 2708.0 \\
\hline Ramnagar & $29.40^{\circ} \mathrm{N}$ & $79.12^{\circ} \mathrm{E}$ & 360 & $-5.33^{*}$ & $-4.94 *$ & $-0.45^{*}$ & 1332.2 \\
\hline Ranikhet & $29.63^{\circ} \mathrm{N}$ & $79.43^{\circ} \mathrm{E}$ & 1824 & +0.29 & +0.25 & -0.08 & 1307.5 \\
\hline Srinagar & $30.22^{\circ} \mathrm{N}$ & $78.78^{\circ} \mathrm{E}$ & 564 & $-1.61 *$ & -1.00 & -0.29 & 886.4 \\
\hline WHR-1902-2005 & - & - & - & $-2.89 *$ & -2.83 & -0.21 & 1565.3 \\
\hline WHR-1902-2000 & - & - & - & $-2.23^{*}$ & $-2.42 *$ & -0.20 & 1582.8 \\
\hline
\end{tabular}


TABLE 2. Different model evaluation method and respective statistical indices to quantify each of the methods.

\begin{tabular}{|c|c|c|}
\hline $\begin{array}{c}\text { Score } \\
\text { No. }\end{array}$ & Method of model evaluation & $\begin{array}{l}\text { Statistical } \\
\text { indices }\end{array}$ \\
\hline 1 & Annual cycle based on mean. & $\begin{array}{c}r \\
d \text { index } \\
\text { NSE } \\
\text { NRMSE }(\%) \\
\text { PBIAS }\end{array}$ \\
\hline 2 & $\begin{array}{l}\text { Annual cycle based on } \\
\text { standard deviation. }\end{array}$ & $\begin{array}{l}\text { Same as } \\
\text { above }\end{array}$ \\
\hline 3 & $\begin{array}{l}\text { Spatial distribution of } \\
\text { monthly rainfall. }\end{array}$ & $r$ \\
\hline 4 & $\begin{array}{l}\text { Spatial distribution of annual } \\
\text { and seasonal rainfall. }\end{array}$ & $r$ \\
\hline 5 & Trend and its magnitude. & $R_{e}$ \\
\hline 6 & SNR & $R_{e}$ \\
\hline
\end{tabular}

method and the overall score calculated through either excluding or including the respective individual method.

\section{1) Evaluation of GCMs}

Following the earlier studies of Palutikof et al. (1997), Das and Lohar (2005), and Das et al. (2012, 2016b), 22 monthly rainfall time series corresponding to the respective station locations were generated through bilinear interpolation technique for each of the GCMs, and finally an aggregated (i.e., area averaged) time series was prepared for the purpose of model evaluation in terms of different statistics. The bilinear interpolation technique uses a minimum of four points from the domain and nearby areas to generate point output from each GCM at each station location. The area-averaged value of the station data as well as area-averaged interpolated GCMs results were used to test the ability of GCMs to reproduce the gross or mean climatic features over the complex topographic region of WHR instead of comparing individual stations with GCM.

All the statistical calculations for the model evaluation were carried out using the empirical statistical downscaling (ESD) package developed by Benestad et al. (2014), which runs in the R environment ( $\mathrm{R}$ Core Team 2014), and the results obtained for different model evaluation methods are described in sections 2d(1)-(4). The ESD package contains $\mathrm{R}$ functions for retrieving data from the NetCDF files, statistical analysis of climate data, and downscaling of monthly mean and daily mean global climate scenarios. (See https://figshare.com/articles/_esd_The_Empirical_ Statistical_Downscaling_tool_amp_its_visualisation_ capabilities_/1454425/1 website for more details.)

\section{2) ANALysis of ANNUAl CyCle}

Two different approaches for annual cycle analysis were used to evaluate the performance of the GCMs:
1) mean annual cycle and 2) annual cycle of interannual variability (i.e., standard deviation). The reason for taking the two different statistics into account is that the temporal pattern of mean annual cycle significantly differs from the temporal pattern of the annual cycle of interannual variability if two datasets have different normalized rootmean-square error (NRMSE) (Stainforth et al. 2007; Smith and Chandler 2010). Mean annual cycle is a very useful method that confirms the ability of a GCM to reproduce the mean monthly climatology, while the dispersion criteria or the standard deviation is used to quantify the similarity of interannual variability between GCMs and observations in a model evaluation study (Giorgi et al. 2004; Fu et al. 2013; Blázquez and Nuñez 2013; Lafaysse et al. 2014). One limitation of analyzing mean annual cycle is that it does not describe the variation of rainfall in different months, while the annual cycle of interannual variability helps to understand the variation of rainfall data in each month separately. Both of these seasonal statistics were prepared using the 1902-2000 interval for both the station data as well as GCMs. For model evaluation, a number of different agreement indices [correlation coefficient $r, d$ index, and Nash-Sutcliffe efficiency (NSE)] and error indices [NRMSE in percent and percentage bias (PBIAS)] were used to quantify the similarity and biases between the GCM and the observed pattern of monthly rainfall.

\section{3) AnAlysis of TREnd}

In addition to the analysis of the annual cycle, the observed short- and longer-term trends, as well as their magnitudes, were compared with the GCMs aggregated over the whole year as well as the monsoon (JJAS) and winter [December-February (DJF)] seasons. The longterm climatic variables of a place may be estimated through an aggregate of short-term fluctuations due to natural/internal variability. While the long-term trends were used to detect climate change signal, the reason for using short-term trends for model evaluation was that internal variability of precipitation tends to be large compared to the expected global warming signal, especially at the local level, and can override the expected signal for decades at a time. The relative error $R_{e}$ was used to quantify how close the magnitude of the Sen's slope of each GCM was to the observed magnitude as suggested by $\mathrm{Fu}$ et al. (2013). The $R_{e}$ is defined as follows:

$$
R_{e}=\frac{X_{\mathrm{GCM}}-X_{\mathrm{Obs}}}{X_{\mathrm{Obs}}}
$$

where $X_{\mathrm{GCM}}$ and $X_{\mathrm{Obs}}$ are the magnitudes of the Sen's slope of GCM and observation, respectively. 
The long-term trend and magnitude were calculated during 1902-2000 (last century) while the short-term trends and magnitudes were calculated for three different 30-yr-long time periods, namely, 1911-40 (1920s), 1941-70 (1950s), and 1971-2000 (1980s).

\section{4) ANALYSis OF SPATIAL CORRELATION}

Spatial correlation coefficients are one of the most commonly used metrics for quantifying the linear relationship between mean fields of observed and simulated precipitation over multiple locations (Srinivasan et al. 1995; Akhter et al. 2016). It was calculated from the vector containing long-term mean rainfall of 22 rain gauge stations (a sample size of 22) and the vector containing long-term mean rainfall of the GCMs (obtained through the bilinear interpolation, at each of the 22 station locations). Section 4 of the supplemental material describes the steps to calculate the spatial correlation. The values of correlations have been calculated both for monthly and seasonal rainfall for the purpose of checking the sensitivity of model evaluation methods in simulating observed rainfall over WHR.

Depending on a given model's resolution, stations may fall in grid points that encompass other stations that are either alike or unlike their neighbors, thus introducing uncertainty. Furthermore, topographic features within a station's respective grid box would influence modeled precipitation differently across different resolutions for that given station. In this study, the main motive of using spatial correlation as a metric is that we want to verify whether the ranks of GCMs based on spatial correlation had any significant bearing on overall rank or not.

\section{5) ANALYSIS OF SNR}

The reliability of a GCM simulation cannot be interpreted solely from its level of agreement with observations. Instead, we have to consider additional factors like internal variability while evaluating a model (Notz 2015).

The relative strength of the anthropogenic climate signal to natural variability can be quantified through the parameter signal-to-noise ratio (SNR), which is the absolute ratio of the linear forced trend to the standard deviation of the residuals of a time series (Schönwiese and Rapp 1997; Maraun 2013; Henson et al. 2016). The residuals correspond to internal variability, whereas the forced trend corresponds to the noise-free signal or climate response. For precipitation, the trends were generally small compared to the interannual variability, and hence a linear trend assumption was used in calculating the SNR (Maraun 2013). The observational data were assumed to contain the most reliable information on climate change, and the ability of the GCMs to simulate the strength of observed climate response was based on a comparison with the observations. The $R_{e}$ was used to quantify how closely the value of SNR of each GCM matched the observations during 1902-2000 for annual, monsoon, and winter season.

\section{d. Ranking of GCMs using different evaluation methods}

The overall ranking of a GCM was achieved through a two-step ranking method as follows:

1) Ranking of individual model evaluation: a rank (1-13 for CMIP3 or 1-42 for CMIP5) was assigned to each GCM based on individual statistical indices within a particular model evaluation method. If a model was evaluated using multiple statistical indices, then the accumulated rank of that model was obtained by the total sum of the ranks based on each individual statistical index. Thereafter, each model secured a rank based on the accumulated rank.

2) Ranking of overall model evaluation: ranking of the overall model evaluation of a GCM was calculated by ranking the sum of individual rank obtained for all the individual model evaluation method.

Rank 1 of a GCM represented the best model, while rank 13 or 42 represents a poor model performance. Rank 0 represented the IMD data.

\section{e. Sensitivity analysis of ranks}

The sensitivity of the rank of each GCM based on different evaluation methods was examined in two different ways as follows:

1) The accuracy of the overall rank was judged by the rank obtained through removing each model evaluation method one by one. The purpose was to check whether the rank is changing through inclusion or exclusion of a particular method in the model evaluation process with respect to the overall rank obtained earlier.

2) The overall rank obtained was compared to the rank obtained for each model evaluation method individually. The purpose was to check whether any individual model evaluation method produced the same rank as the overall model evaluation method.

\section{The results}

\section{a. Observed rainfall analysis (1902-2005)}

The analysis of 22 stations' mean rainfall showed that the WHR has experienced annual rainfall of approximately $1565.3 \pm 476.6 \mathrm{~mm}$ in the last century; the rainfall 
received during the monsoon season was approximately $1250.1 \pm 241.7 \mathrm{~mm}$. So the monsoon rainfall over WHR has contributed $79.8 \%$ of the total annual rainfall. Similar results were obtained by Singh and Kumar (1997), over the Sutlej and Beas River basins in the WHR. The mean rainfall in the winter months (DJF) was $139.4 \pm 65.3 \mathrm{~mm}$, which was about $11 \%$ of the annual rainfall. The analysis of mean annual cycle (see Fig. 2a) showed that the WHR got a maximum (about one-quarter) of annual rainfall in August while rainfall during the November was the minimum. In the months of January-March and in May, the region has experienced marginally uniform rainfall ( $\sim 3.5 \%$ of total annual rainfall). To measure the spread that describes the amount of variability of the observational data relative to its mean, the coefficient of variation (CV) that is expressed as the standard deviation divided by the mean and is calculated for annual and seasonal rainfall. It was noticed that the value of $\mathrm{CV}$ was highest for winter rainfall, whereas it was lowest for annual rainfall. The CV of monsoon rainfall was found in the range between the CV of winter and annual rainfall for all the stations.

The results of stationwise annual and seasonal rainfall change are given in Table 1 . There was a clear statistically significant negative (at $5 \%$ ) trend over the period 1905-2005 of annual rainfall amount in 10 stations, monsoon rainfall in 12 stations, and winter rainfall in 7 stations. The WHR received significant negative trends of monsoon rainfall amount by $-283.4 \mathrm{~mm}(100 \mathrm{yr})^{-1}$ and annual rainfall totals by $-289.3 \mathrm{~mm}(100 \mathrm{yr})^{-1}$ during 1902-2005. Winter rainfall has also shown a nominal negative trend of $-21.7 \mathrm{~mm}(100 \mathrm{yr})^{-1}$.

It is worth noting that IMD stations are likely biased toward sampling monsoon precipitation. Monsoon convection over foothills and low elevations is better sampled by the gauge network compared to winter precipitation, which is orographically enhanced and occurs preferentially at high elevations that are not well sampled. Numerous studies have noted undersampling of winter precipitation in the western Himalayas (Barros et al. 2006; Lang and Barros 2004; Bookhagen and Burbank 2010).

\section{b. Model evaluation}

All the GCMs were evaluated using the methods described in sections $2 c(1)-(5)$, and the results are discussed in the following sections.

\section{1) COMPARISON OF ANNUAL CYCLE}

Table 3 summarizes the comparison between different statistical measures of the mean annual cycles of monthly rainfall as well as the annual cycles of interannual variability of rainfall for different GCMs. All these statistical measures were calculated from each GCM simulation and compared with the observed values of the regionally averaged rainfall of 22 stations during the period 1902-2000.

\section{(i) Analysis of mean annual cycle}

Figure 2a shows the seasonal variations in the mean rainfall simulated by the CMIP3 and CMIP5 GCMs. It shows that the CMIP3 GCMs failed to capture the observed annual cycle during all the months while CMIP5 GCMs have shown improvement in simulating the observed pattern of rainfall. The quantitative analysis of Fig. 2a showed that the PBIAS in CMIP3 GCMs varied from $-23.7 \%$ to $-76.2 \%$ (Table 3 ), which indicates CMIP3 GCMs underestimated the observed mean annual cycle. The NRMSE value ranged from 57.0 to 122.3 , the smaller value of NRMSE is indicating a better fit between the GCMs and the observed mean annual cycle. The GCMs CNRM-CM3, GFDL CM2.0, GFDL CM2.1, and the high-resolution version of the MIROC3.2 model [MIROC3.2 (hires)] had consistently produced higher values of NSE, $d$ index, and $r$ and lower values of PBIAS and NRMSE, indicating good abilities to reproduce the observed mean annual cycle. The GCMs BCCR-BCM2.0, CCCma CGCM3.1 (T47), and IPSL-CM4, despite having the highest values of correlation coefficient $(0.95,0.88$ and 0.52 , respectively), failed to reproduce the other agreement indices and also showed high values of NRMSE and PBIAS. The mean annual cycles simulated by four GCMs (INGV ECHAM4, INM-CM3.0, and UKMO HadCM3 and HadGEM1) showed a negative correlation with the observations. Similar results have been found in other parts of the globe [e.g., the African monsoon region (Fontaine et al. 2011); Indus, Ganges, and Brahmaputra River basins (Hasson et al. 2013, 2016); and Karnataka region of India (Mehrotra et al. 2013)]. The models INM-CM3.0 and IPSL-CM4 were characterized by profound water balance inconsistencies; hence the estimates of their projection under a warming climate may introduce further biases to the regional climate simulations (Hasson et al. 2013, 2016). Previous model evaluation over Australian region by Suppiah et al. (2007) and Smith and Chiew (2009) has shown that the CSIRO Mk3.0, INM-CM4.0, and IPSL-CM4 GCMs performed worse than the rest of the group of GCMs included in this study. This assessment was primarily an evaluation of GCMs by comparison with the observed mean annual rainfall and sea level pressure.

The set of CMIP5 GCMs that includes CCSM4, CESM1(BGC), CESM1(CAM5), MIROC5, MIROCESM-CHEM, NorESM1-M, and NorESM1-ME have shown low error indices compared to others. Furthermore, 
TABLE 3. Model performance through annual cycle analysis during 1902-2000. (Expansions of acronyms are available online at https:// www.ametsoc.org/PubsAcronymList. For GISS models, p1, p2, and p3 in parentheses indicate the physics package used by the model.)

\begin{tabular}{|c|c|c|c|c|c|c|c|c|c|c|}
\hline & \multicolumn{5}{|c|}{ Annual cycle of mean } & \multicolumn{5}{|c|}{ Annual cycle of std dev } \\
\hline & $r$ & $d$ index & NSE & NRMSE (\%) & PBIAS (\%) & $r$ & $d$ index & NSE & NRMSE (\%) & PBIAS (\%) \\
\hline \multicolumn{11}{|l|}{ CMIP3 } \\
\hline BCCR-BCM2.0 & 0.95 & 0.58 & 0.16 & 88.0 & -62.4 & 0.62 & 0.55 & -0.47 & 115.9 & -55.6 \\
\hline CGCM3.1 (T47) & 0.88 & 0.50 & 0.08 & 92.0 & -55.9 & 0.70 & 0.56 & -0.20 & 104.9 & -44.1 \\
\hline CNRM-CM3 & 0.98 & 0.57 & 0.27 & 82.0 & -42.9 & -0.37 & 0.39 & -0.96 & 134.1 & -51.0 \\
\hline CSIRO Mk3.0 & 0.01 & 0.41 & -0.36 & 111.6 & -67.3 & 0.06 & 0.44 & -0.54 & 119.0 & -43.6 \\
\hline CSIRO Mk3.5 & 0.03 & 0.41 & -0.31 & 109.5 & -61.1 & 0.28 & 0.48 & -0.23 & 106.1 & -32.4 \\
\hline GFDL CM2.0 & 0.94 & 0.78 & 0.53 & 65.9 & -36.9 & 0.58 & 0.59 & 0.07 & 92.1 & -29.6 \\
\hline GFDL CM2.1 & 0.92 & 0.84 & 0.65 & 57.0 & -23.7 & 0.75 & 0.84 & 0.56 & 63.5 & -5.0 \\
\hline ECHAM4 & -0.38 & 0.28 & -0.61 & 121.5 & -46.9 & 0.09 & 0.47 & -0.61 & 121.3 & -48.0 \\
\hline INM-CM3.0 & -0.83 & 0.37 & -0.63 & 122.3 & -76.2 & -0.65 & 0.37 & -1.46 & 150.1 & -60.8 \\
\hline IPSL-CM4 & 0.52 & 0.47 & -0.09 & 100.2 & -60.8 & 0.41 & 0.56 & -0.22 & 105.7 & -36.4 \\
\hline MIROC3.2 (hires) & 0.93 & 0.64 & 0.34 & 77.7 & -41.1 & 0.91 & 0.64 & 0.22 & 84.7 & -31.4 \\
\hline HadCM3 & -0.17 & 0.30 & -0.58 & 120.2 & -27.4 & -0.16 & 0.34 & -0.60 & 121.1 & -20.6 \\
\hline HadGEM1 & -0.07 & 0.37 & -0.37 & 112.1 & -60.7 & -0.23 & 0.34 & -0.77 & 127.4 & -35.8 \\
\hline \multicolumn{11}{|l|}{ CMIP5 } \\
\hline ACCESS1.0 & 0.92 & 0.86 & 0.68 & 53.8 & -12.0 & 0.72 & 0.65 & 0.28 & 81.5 & -22.8 \\
\hline ACCESS1.3 & 0.82 & 0.67 & 0.38 & 75.3 & -31.4 & 0.60 & 0.66 & 0.20 & 85.7 & -24.0 \\
\hline BCC_CSM1.1 & -0.22 & 0.39 & -0.46 & 115.5 & -72.7 & 0.16 & 0.46 & -0.51 & 117.8 & -45.2 \\
\hline BCC_CSM1.1(m) & 0.86 & 0.51 & 0.12 & 90.0 & -53.4 & 0.80 & 0.72 & 0.39 & 74.7 & -22.8 \\
\hline BNU-ESM & 0.91 & 0.63 & 0.29 & 80.6 & -48.6 & 0.79 & 0.81 & 0.55 & 64.3 & -11.4 \\
\hline CanESM2 & 0.79 & 0.49 & -0.12 & 101.3 & -67.7 & 0.51 & 0.49 & -1.11 & 139.2 & -69.6 \\
\hline CCSM4 & 0.99 & 0.98 & 0.93 & 25.5 & -4.3 & 0.84 & 0.60 & -0.27 & 107.8 & -53.3 \\
\hline CESM1(BGC) & 0.99 & 0.98 & 0.93 & 25.9 & -4.6 & 0.88 & 0.91 & 0.73 & 49.7 & 10.5 \\
\hline CESM1(CAM5) & 0.99 & 0.95 & 0.86 & 35.3 & -20.2 & 0.87 & 0.70 & 0.10 & 90.9 & -45.2 \\
\hline CMCC-CM & 0.63 & 0.42 & 0.02 & 94.6 & -45.7 & 0.35 & 0.49 & 0.09 & 91.3 & -10.3 \\
\hline CMCC-CMS & 0.41 & 0.38 & -0.07 & 99.0 & -47.2 & 0.04 & 0.31 & -0.13 & 101.8 & -2.5 \\
\hline CNRM-CM5 & 0.97 & 0.69 & 0.42 & 73.1 & -35.5 & 0.51 & 0.46 & 0.10 & 91.0 & -18.8 \\
\hline CSIRO Mk3.6.0 & -0.81 & 0.42 & -0.64 & 122.7 & -88.3 & -0.72 & 0.44 & -2.20 & 171.4 & -90.4 \\
\hline EC-EARTH & 0.91 & 0.85 & 0.65 & 56.7 & -24.7 & 0.52 & 0.51 & -0.96 & 134.0 & -65.2 \\
\hline FGOALS-g2 & -0.18 & 0.4 & -0.33 & 110.3 & -64.9 & 0.35 & 0.47 & -0.48 & 116.5 & -46.3 \\
\hline FIO-ESM & 0.77 & 0.52 & 0.19 & 86.1 & -40.2 & 0.64 & 0.54 & -0.35 & 111.4 & -48.8 \\
\hline GFDL CM3 & 0.85 & 0.71 & 0.44 & 71.6 & -31 & 0.63 & 0.72 & 0.38 & 75.5 & -7.2 \\
\hline GFDL-ESM2G & 0.91 & 0.83 & 0.59 & 61.1 & -34.9 & 0.91 & 0.95 & 0.83 & 39.3 & -3.8 \\
\hline GFDL-ESM2M & 0.91 & 0.76 & 0.49 & 68.4 & -38.8 & 0.91 & 0.94 & 0.81 & 41.2 & 0.5 \\
\hline GISS-E2-H (p1) & -0.71 & 0.38 & -0.55 & 119.1 & -73.8 & -0.92 & 0.41 & -1.95 & 164.6 & -80.0 \\
\hline GISS-E2-H (p2) & -0.75 & 0.37 & -0.57 & 119.9 & -73.9 & -0.94 & 0.41 & -1.94 & 164.2 & -79.0 \\
\hline GISS-E2-H (p3) & -0.66 & 0.39 & -0.56 & 119.4 & -76.1 & -0.89 & 0.41 & -1.97 & 164.9 & -80.8 \\
\hline GISS-E2-H-CC & -0.71 & 0.37 & -0.55 & 119.4 & -73.2 & -0.91 & 0.31 & -1.45 & 150.0 & -54.0 \\
\hline GISS-E2-R (p1) & -0.78 & 0.37 & -0.58 & 120.2 & -74.4 & -0.93 & 0.41 & -2.03 & 166.7 & -82.6 \\
\hline GISS-E2-R (p2) & -0.81 & 0.37 & -0.59 & 120.8 & -75.1 & -0.95 & 0.41 & -1.99 & 165.6 & -81.6 \\
\hline GISS-E2-R (p3) & -0.79 & 0.38 & -0.58 & 120.2 & -76.0 & -0.93 & 0.42 & -2.03 & 166.7 & -83.1 \\
\hline GISS-E2-R-CC & -0.76 & 0.37 & -0.58 & 120.2 & -74.2 & -0.91 & 0.33 & -1.57 & 153.5 & -59.1 \\
\hline HadGEM2-AO & 0.93 & 0.9 & 0.74 & 48.8 & -12.8 & 0.63 & 0.57 & 0.19 & 86.1 & -22.4 \\
\hline HadGEM2-CC & 0.89 & 0.85 & 0.65 & 56.6 & -15.0 & 0.71 & 0.62 & 0.19 & 86.3 & -28.0 \\
\hline HadGEM2-ES & 0.91 & 0.86 & 0.67 & 55.3 & -17.4 & 0.71 & 0.53 & -0.71 & 125.3 & -62.0 \\
\hline INM-CM4.0 & 0.86 & 0.62 & 0.31 & 79.3 & -38.5 & 0.19 & 0.50 & -0.20 & 104.9 & -20.0 \\
\hline IPSL-CM5A-LR & -0.04 & 0.38 & -0.32 & 109.9 & -61.2 & -0.02 & 0.43 & -0.81 & 128.8 & -51.3 \\
\hline IPSL-CM5A-MR & 0.35 & 0.44 & -0.26 & 107.4 & -67.4 & 0.07 & 0.41 & -0.38 & 112.4 & -24.1 \\
\hline IPSL-CM5B-LR & -0.73 & 0.26 & -0.63 & 122.4 & -56.0 & -0.78 & 0.10 & -1.62 & 155.0 & -14.2 \\
\hline MIROC5 & 0.98 & 0.91 & 0.78 & 45.2 & -22.2 & 0.90 & 0.69 & 0.08 & 92.1 & -46.2 \\
\hline MIROC-ESM & 0.92 & 0.91 & 0.75 & 47.6 & 11.8 & 0.46 & 0.51 & 0.21 & 85.3 & 4.7 \\
\hline $\begin{array}{l}\text { MIROC-ESM- } \\
\text { CHEM }\end{array}$ & 0.92 & 0.91 & 0.76 & 46.8 & 7.8 & 0.52 & 0.60 & 0.27 & 81.9 & 2.7 \\
\hline MPI-ESM-LR & 0.95 & 0.67 & 0.36 & 76.4 & -42.6 & 0.63 & 0.53 & -0.44 & 115.0 & -50.8 \\
\hline MPI-ESM-MR & 0.9 & 0.63 & 0.33 & 78.3 & -38.8 & 0.62 & 0.53 & -0.27 & 107.8 & -44.3 \\
\hline MRI-CGCM3 & -0.55 & 0.38 & -0.48 & 116.3 & -72.0 & -0.19 & 0.40 & -0.68 & 124.2 & -46.1 \\
\hline NorESM1-M & 0.95 & 0.92 & 0.79 & 43.6 & -17.0 & 0.86 & 0.92 & 0.70 & 52.3 & 9.0 \\
\hline NorESM1-ME & 0.95 & 0.94 & 0.82 & 40.4 & -14.3 & 0.85 & 0.91 & 0.69 & 53.3 & 8.8 \\
\hline
\end{tabular}




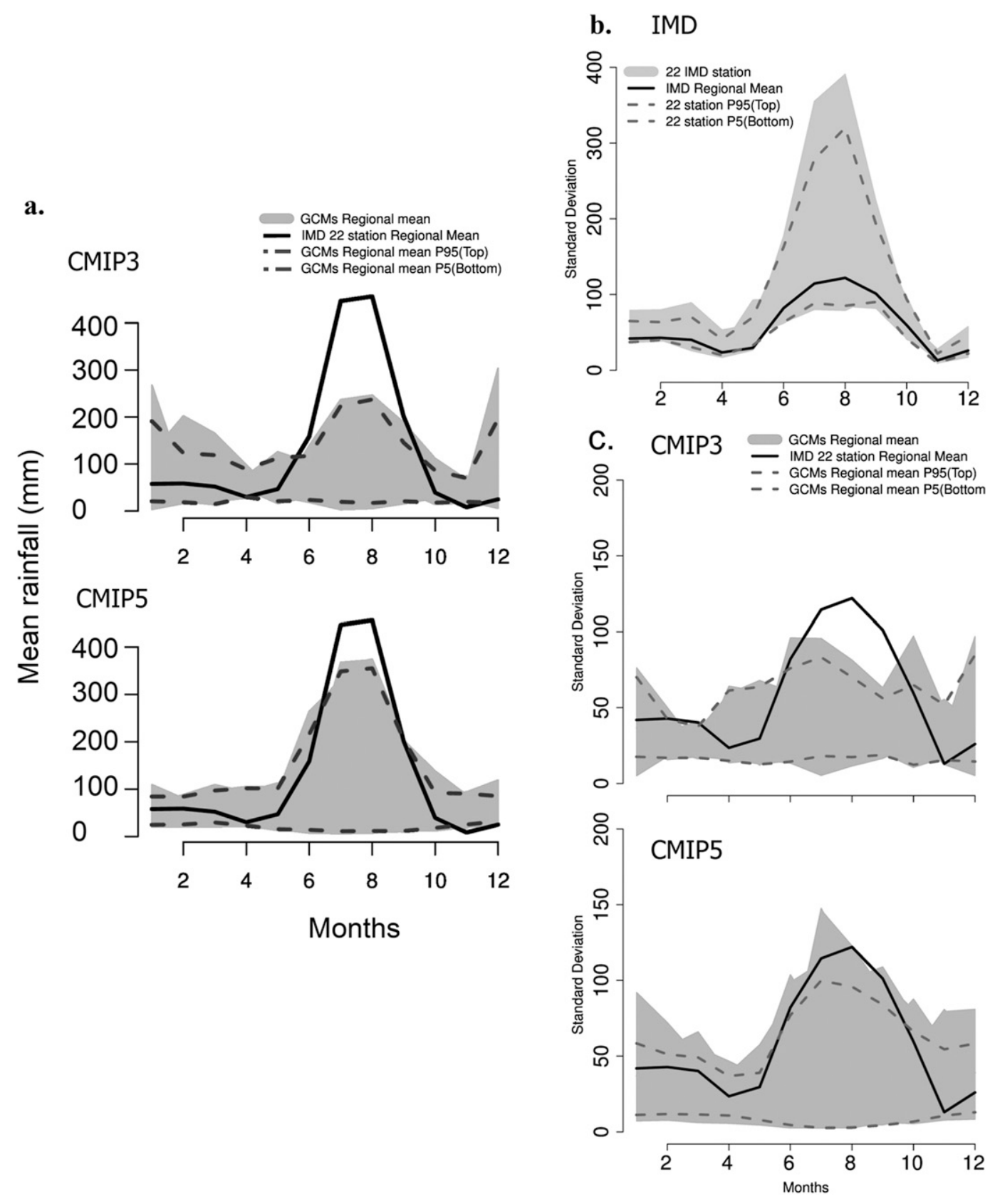

FIG. 2. (a) Variation of the monthwise regionally averaged rainfall from the ensemble of CMIP3 and CMIP5 GCMs. Variation of the monthly standard deviation of rainfall ( $\mathrm{mm}$ ) for (b) IMD station data and (c) CMIP3 and CMIP5 simulations. The thick black line in each plot represents the regional average of 22 IMD stations. Upper and lower dashed lines show the 95th percentile and 5th percentile of respective datasets, respectively. The variation of the monthly standard deviation of all the 22 stations is shown by shaded gray color in (b), whereas the shaded gray color in (c) shows the variation of the monthly standard deviation of all the individual GCMs.

MIROC-ESM and MIROC-ESM-CHEM have shown positive PBIAS with respect to the observation, which suggests that they tend to overestimate the rainfall amounts. Most of the GCMs in CMIP3 and CMIP5 have shown higher dry biases specifically in peak rainfall months (i.e., July and August; Fig. 2a). The French CNRM-CM5 model, the British HadGEM models, and Japanese MIROC have shown improvement over the two generations from CMIP3 to CMIP5 in terms of their ability to simulate the observed mean annual cycle as they 
have a higher value of agreement indices and lower value of error indices in CMIP5 than CMIP3. BCC_CSM1.1, CanESM2, CSIRO Mk3.6.0, FGOALS-g2, eight GISSE2 version models, IPSL-CM5A-LR, IPSL-CM5B-LR, and MRI-CGCM3 had a negative correlation with observation and higher values of PBIAS.

\section{(ii) Analysis of annual cycle of interannual variability}

Figure $2 \mathrm{~b}$ shows the seasonal variations in the standard deviation of observed rainfall and provides an indication of the interannual variability. The standard deviation was high for the observations during JuneAugust and low in November, December, March, April, and May months. Figure 2c shows that the CMIP3 GCMs failed to capture the observed pattern of interannual variability during all the months. The standard deviation of the observations was maximum in August and minimum in November while most of the CMIP3 GCMs showed the maximum value in December and the minimum value in March. Interannual variations of rainfall over a land area are mainly driven by the sea surface temperature (SST) anomalies over the surrounding oceans (Joetzjer et al. 2013), and there is a strong relationship between SST and rainfall. An inaccurate representation of rainfall-SST teleconnection in GCMs may explain the discrepancy between observed and model-simulated interannual variability of rainfall (Annamalai et al. 2007). The results for CMIP3 GCMs indicated larger errors with different GCMs exhibiting a different pattern of interannual variability than observed and in most of the cases underestimating the observation in wet or monsoon months. Table 3 presents the correlation coefficients between CMIP3 GCMs and observed interannual variability and shows that they ranged from -0.37 to 0.91 . These values were low compared to the values obtained in "mean annual cycle" method of model evaluation. Only two GCMs [GFDL CM2.0 and MIROC3.2 (hires)] had higher values of correlation and lower errors. Most of the GCMs showed negative values of NSE, which indicates that the observed mean was a better predictor than the model mean. Over the Indian subcontinent, the CMIP3 GCMs underestimated the standard deviation during monsoon months because of poor simulations in their temporal and interannual variability and extremes (Shashikanth et al. 2014).

Figure $2 b$ shows that the CMIP5 GCMs were better at capturing the observed pattern of interannual variability in all months than the CMIP3 GCMs. The 95th percentile (p95) of the model standard deviation was very close to the observed standard deviation except in November and December. CMIP5 GCMs had nominal positive biases in the winter and premonsoon months while negative biases were seen in the monsoon months. On the other hand, the 5th percentile (p5) of the model standard deviation exhibited an opposite pattern of interannual variability compared to observed variability. These patterns can be explained by poor simulation of the rainfall in GISS (eight versions), IPSL (two versions), CSIRO Mk3.6.0 and MRI-CGCM3 models. Six models [BNU-ESM, CESM1(BGC), GFDL-ESM2G, GFDL-ESM2M, NorESM1-M, and NorESM1-ME] had consistently high value of $r(>0.78), d$ index $(>0.80)$, and NSE $(>0.54)$. The corresponding NRMSE values were low; however, the PBIAS values were mostly positive. Of the GCMs in CMIP5, 55\% had a correlation coefficient greater than 0.50 , compared to $38 \%$ for CMIP3.

\section{2) COMParison of tRends}

Table 4 summarizes the comparison between simulated and observed long-term (i.e., $99 \mathrm{yr}$ ) and short-term (i.e., $30 \mathrm{yr}$ ) trends. The observational rainfall data showed a significant (at 10\%) negative trend during 1902-2000 annually and in the monsoon season, whereas the winter rainfall has shown a nonsignificant negative trend. The station data also showed a negative trend of rainfall annually and in the monsoon season during different short-term periods, that is, the 1920s and 1950, while positive trends were noticed in the 1980s for the annual and winter.

Seven GCMs of CMIP3 were able to simulate the negative trend of observed annual rainfall during 19022000, but only MIROC3.2 (hires) has shown a significant result. Other GCMs (CNRM-CM3 and GFDL CM2.1 during the 1920s, GFDL CM2.0 during the 1950s, and BCCR-BCM2.0 and CSIRO Mk3.0 during the 1980s) were able to reproduce the observed annual rainfall trends. The GCMs that had a minimum value of $R_{e}$ for annual rainfall were MIROC3.2 (hires) during the 1920s and 1950s, CGCM3.1 (T47) during the 1980s, and HadCM3 during 1902-2000. In the case of the annual rainfall totals, IPSL-CM4 exhibited a maximum value of $R_{e}$ in the short-term period while CGCM3.1 (T47) showed maximum value for a long-term period. Three GCMs (GFDL CM2.1, IPSL-CM4, and HadCM3) indicated negative monsoon rainfall trends like the observations during the 1980s. Some models like ECHAM4, MIROC3.2 (hires), INM-CM3.0, GFDL CM2.0, and GFDL CM2.1 were able to reproduce the observed monsoon rainfall trends in all time periods. ECHAM4, HadGEM1, and INM-CM3.0 had minimum values of $R_{e}$ while CSIRO Mk3.5, IPSL-CM4, and GFDL CM2.1 had maximum values of $R_{e}$ for monsoon rainfall trends during the 1920s, 1950s, and 1980s, 
respectively. In the long term, GFDL CM2.1 had minimum and CSIRO Mk3.5 had a maximum value of $R_{e}$ for monsoon rainfall amounts. In the winter season, 5 out of 13 CMIP3 GCMs were able to simulate the observed long-term rainfall trend out of which CNRM-CM3 and HadCM3 had only significant (at 10\%) trend. Three GCMs (INM-CM3.0 during the 1950s and BCCRBCM2.0 and GFDL CM2.1 during 1980s) were only able to simulate the observed winter rainfall trends. The GCMs that gave a minimum value of $R_{e}$ for winter rainfall included INM-CM3.0 during the 1920s and 1980s, ECHAM4 during the 1950s, and CSIRO Mk3.5 during 1902-2000. In general, none of the CMIP3 GCMs was able to simulate the observed trend and magnitude of Sen's slope adequately, but MIROC3.2 (hires) and ECHAM4 showed better results (low relative error) than the other GCMs.

Similar to CMIP3, the abilities of the CMIP5 models to reproduce observed rainfall in different seasons and annual scale is summarized in Table 4. Of the 42 GCMs, 17 were able to simulate the long-term observed annual rainfall trends while 3 of those (HadGEM2-AO, HadGEM2-ES, and IPSL-CM5B-LR) were significant (at $10 \%$ ). The ones that had a minimum value of $R_{e}$ for annual rainfall were MPI-ESM-MR during the 1920s, GFDL CM3 during the 1950s, BCC_CSM1.1(m) during the 1980s, and HadGEM2-AO during 19022000. NorESM1-M and CESM1(CAM5) GCMs were characterized by maximum value of $R_{e}$ for all short- and long-term periods of the annual rainfall. In the monsoon season, ACCESS1.3 has shown a significant long-term negative trend like the observations. ACCESS1.3, CSIRO Mk3.6.0, all HadGEM2 version models, MIROC-ESM, and MPI-ESM-MR have shown negative monsoon rainfall trends (significant at $10 \%$ ) like the observations during the 1950s. During the 1920s and 1980s, CMIP5 GCMs failed to reproduce significant negative monsoon rainfall trends of observation. MPI-ESM-LR and BCC_CSM1.1 had minimum values of $R_{e}$, while NorESM1-M and HadGEM2-AO had maximum values of $R_{e}$ for monsoon rainfall trends during the $1920 \mathrm{~s}$ and $1950 \mathrm{~s}$, respectively. Similarly, HadGEM2-ES had minimum and CESM1(CAM5) had maximum value of $R_{e}$ for monsoon rainfall during 19022000. In the winter season, 15 CMIP5 GCMs were able to simulate the observed long-term trend out of which CSIRO Mk3.6.0, HadGEM2-AO, and MIROC5 had only significant (at $10 \%$ ) trend. GCMs, namely, GISSE2-R (p1) during the 1920s and CanESM2 during the 1950 s, were only able to simulate (significant at $10 \%$ ) the observed winter rainfall trends. The GCMs that are having minimum value of $R_{e}$ for winter rainfall are INMCM4.0 during the 1920s, CanESM2 during the 1950s,
BNU-ESM during the 1980s, and MRI-CGCM3 during 1902-2000. Overall, five GCMs, namely, ACCESS1.0, CESM1(BGC), HadGEM2-CC, MIROC5, and MPIESM-MR, were able to simulate the observed trends in most of the time period (except during 1971-2000), but the magnitude of their Sen's slopes either overestimated or underestimated the observation. For GCMs like CanESM2 and IPSL-CM5B-LR, the $R_{e}$ was less than other GCMs.

\section{3) COMPARISON OF SPATIAL CORRELATION}

Table 5 summarizes the spatial correlation coefficients of monthly, annual, and seasonal rainfall. Four CMIP3 GCMs [MIROC3.2 (hires), GFDL CM2.0, CGCM3.1 (T47) and CSIRO Mk3.5] had high spatial correlation values (i.e., 0.57-0.90) during January-June and November-December and especially $(0.79-0.86)$ during the winter season. The spatial correlation for three GCMs (HadGEM1, HadCM3, and ECHAM4) was $<0.13$ irrespective of the monthly, annual, or seasonal distribution of rainfall. Almost $70 \%$ of the CMIP3 GCMs had higher correlation values $(r>0.50)$ during March and April months but had low correlations during July-October months.

For CMIP5, approximately $93 \%$ of the GCMs gave a spatial correlation value $>0.6$ in March and April. Similarly, approximately $64 \%$ of the GCMs had correlation coefficient $>0.5$ in the January, February, November, and December as well as during the winter season. All the GCMs had low correlations $(<0.20)$ in July and August. The annual and monsoon spatial rainfall distribution in all the GCMs were different from the observed pattern, and the spatial correlations were mostly negative and all were $<0.20$.

Figure S2 of the supplemental material shows the annual cycle of spatial correlation for all the GCMs of CMIP3 and CMIP5. It shows a unique variation of the spatial correlation among different months. The interquartile range (IQR; difference between 3rd and 1st quartile) was maximum during December and decreased up to March, and then it again started to increase and attended a maximum value in June. The spatial correlation values were found to increase from December to March, there was a decreasing pattern from March to August while an increasing pattern of spatial correlation was observed from August to December. The spatial correlation of the winter season was higher than the monsoon season, and the annual rainfall distribution was poorly simulated by all the GCMs with low and mostly negative correlation coefficients. The low correlation in some months may be a result of high interannual variability of rainfall in these months. 
TABLE 4. Model performance through short-term (30 yr) and long-term (99 yr) trend analysis. Asterisks indicate significance at $10 \%$.

\begin{tabular}{|c|c|c|c|c|c|c|c|c|c|c|c|c|}
\hline & \multicolumn{12}{|c|}{ Trend (with Sen's slope) } \\
\hline & \multicolumn{4}{|c|}{ Annual } & \multicolumn{4}{|c|}{ Monsoon } & \multicolumn{4}{|c|}{ Winter } \\
\hline & $\begin{array}{c}1911- \\
40\end{array}$ & $\begin{array}{c}1941- \\
70\end{array}$ & $\begin{array}{c}1971- \\
2000\end{array}$ & $\begin{array}{c}1902- \\
2000\end{array}$ & $\begin{array}{c}1911- \\
40\end{array}$ & $\begin{array}{c}1941- \\
70\end{array}$ & $\begin{array}{c}1971- \\
2000\end{array}$ & $\begin{array}{c}1902- \\
2000\end{array}$ & $\begin{array}{c}1911- \\
40\end{array}$ & $\begin{array}{c}1941- \\
70\end{array}$ & $\begin{array}{c}1971- \\
2000\end{array}$ & $\begin{array}{c}1902- \\
2000\end{array}$ \\
\hline \multicolumn{13}{|l|}{ CMIP3 } \\
\hline BCCR-BCM2.0 & 1.91 & -0.12 & $3.42 *$ & 0.04 & 0.90 & 0.46 & -1.48 & -0.25 & 0.21 & -0.14 & $3.75^{*}$ & $0.36^{*}$ \\
\hline CGCM3.1 (T47) & 0.12 & $5.85^{*}$ & 0.75 & 0.49 & 1.96 & 0.42 & 2.28 & 0.36 & -1.21 & 0.94 & -1.72 & 0.10 \\
\hline CNRM-CM3 & $-4.45^{*}$ & 0.67 & 1.65 & -0.58 & -0.44 & -1.33 & $2.04 *$ & 0.04 & $-3.49 *$ & 1.63 & -1.89 & $-0.67 *$ \\
\hline CSIRO Mk3.0 & 1.61 & 1.55 & $6.49 *$ & 0.10 & -1.73 & 1.87 & $2.80 *$ & -0.01 & 0.16 & 1.11 & -0.74 & 0.01 \\
\hline CSIRO Mk3.5 & 3.63 & 1.11 & 2.64 & -0.19 & $4.75^{*}$ & 1.32 & 1.94 & 0.43 & -0.54 & 1.26 & -0.41 & -0.19 \\
\hline GFDL CM2.0 & 0.04 & $-4.31 *$ & -3.33 & 0.27 & -0.12 & -0.70 & -1.62 & -0.08 & 0.26 & -0.17 & -1.59 & 0.00 \\
\hline GFDL CM2.1 & $-8.50 *$ & 1.15 & -0.74 & -0.29 & -2.46 & -1.33 & $-10.33 *$ & -1.20 & -1.51 & 0.95 & $2.86^{*}$ & 0.24 \\
\hline ECHAM4 & 0.05 & -3.30 & 0.62 & 0.06 & -0.86 & -0.11 & -0.90 & -0.22 & -0.97 & -1.77 & -1.46 & 0.01 \\
\hline INM-CM3.0 & 1.56 & -1.24 & 0.31 & 0.42 & -0.20 & 0.59 & -0.32 & 0.08 & 1.43 & $-3.68 *$ & 0.73 & 0.12 \\
\hline IPSL-CM4 & $8.86^{*}$ & $10.09 *$ & -5.29 & -0.09 & 1.44 & $5.81^{*}$ & $-3.84 *$ & -0.08 & 0.18 & -0.07 & -0.03 & -0.02 \\
\hline MIROC3.2(hires) & -2.75 & -1.35 & -2.58 & $-0.69 *$ & -4.18 & -0.06 & -2.49 & -0.67 & 1.17 & 1.61 & -0.23 & -0.26 \\
\hline HadCM3 & -5.30 & -3.49 & -2.30 & -0.72 & 0.36 & -0.85 & $-5.01 *$ & 0.26 & $-7.83 *$ & -2.87 & -1.83 & $-1.91 *$ \\
\hline HadGEM1 & $5.53 *$ & -1.19 & -1.20 & -0.06 & 2.74 & -1.23 & -0.52 & -0.12 & -0.08 & 0.97 & -0.72 & 0.24 \\
\hline \multicolumn{13}{|l|}{ CMIP5 } \\
\hline ACCESS1.0 & 2.95 & -1.48 & 2.35 & -0.49 & -0.27 & -3.60 & 1.70 & -0.58 & 2.84 & 0.11 & 0.67 & 0.17 \\
\hline ACCESS1.3 & 2.54 & $-7.97 *$ & -1.08 & -0.65 & 1.41 & $-8.36^{*}$ & 0.14 & $-0.81 *$ & 0.42 & -1.59 & -0.97 & -0.10 \\
\hline BCC_CSM1.1 & -1.43 & -1.39 & -0.49 & -0.02 & 0.07 & -1.12 & -2.16 & 0.35 & -1.67 & 1.25 & -0.99 & -0.10 \\
\hline BCC_CSM1.1(m) & & & & & & & & 0.48 & -2.60 & -2.28 & & 0.01 \\
\hline BNU-ESM & 5.90 & 2.22 & 1.84 & 0.91 & 2.53 & 2.64 & 3.43 & 0.65 & -0.89 & 1.43 & 1.44 & 0.20 \\
\hline CanESM2 & -1.19 & 0.19 & 0.52 & -0.31 & 0.03 & 1.32 & 1.14 & -0.30 & -0.25 & $-1.03^{*}$ & -0.03 & -0.10 \\
\hline CCSM4 & -1.95 & -3.51 & 1.77 & 0.20 & 2.47 & -3.12 & 0.55 & 0.31 & -0.40 & -0.30 & -0.34 & 0.02 \\
\hline I1(BGC) & & & 3.43 & -0. & -2.44 & & & & -2.55 & & & -0.23 \\
\hline CESM1(CAM5) & 2.00 & 0.87 & 1.67 & $1.61 *$ & 3.11 & -0.69 & 2.87 & $1.21 *$ & 0.34 & 1.42 & -0.17 & $0.24 *$ \\
\hline CMCC-CM & -5.61 & 0.09 & 4.74 & 0.79 & -2.87 & -2.00 & 3.05 & 0.63 & 0.18 & 1.46 & 1.39 & 0.35 \\
\hline CMCC-CMS & -3.65 & -2.49 & 6.09 & 0.22 & 1.76 & 2.76 & 4.26 & 0.66 & -2.05 & -5.61 & 1.14 & -0.42 \\
\hline CNRM-CM5 & 2.27 & 2.34 & 1.30 & 0.13 & -0.03 & 3.08 & -1.60 & 0.00 & 1.04 & -0.90 & 2.68 & 0.05 \\
\hline CSIRO Mk3.6.0 & -0.16 & -0.52 & $0.85^{*}$ & 0.02 & 0.21 & $-0.30 *$ & $0.70 *$ & $0.08 *$ & -0.37 & -0.24 & -0.04 & $-0.08^{*}$ \\
\hline EC-EARTH & 2.98 & 1.67 & 0.90 & $0.77 *$ & -0.15 & 1.42 & 0.57 & $0.84 *$ & 1.20 & 0.10 & -0.38 & -0.06 \\
\hline FGOALS-g2 & 3.37 & -0.20 & 3.80 & $1.17 *$ & 0.80 & -0.33 & $3.44 *$ & $0.47 *$ & 0.87 & 0.70 & 0.04 & 0.20 \\
\hline FIO-ESM & -0.22 & $-3.52 *$ & 0.79 & 0.37 & -0.58 & -1.43 & 0.80 & 0.34 & -0.58 & -1.80 & -0.45 & -0.05 \\
\hline GFDL CM3 & 4.91 & -1.75 & -4.22 & 0.08 & 1.98 & -0.62 & -3.47 & -0.35 & -0.05 & -0.39 & 0.50 & 0.14 \\
\hline GFDL-ESM2G & 1.12 & 3.00 & 11.42 & -0.35 & -2.42 & 2.41 & $10.19^{*}$ & -0.66 & 0.47 & -0.03 & -0.27 & 0.06 \\
\hline GFDL-ESM2M & -0.32 & 0.03 & -1.18 & & 2.47 & & -0.96 & & -0.52 & 0.16 & -0.55 & 0.07 \\
\hline GISS-E2-H (p1) & -0.40 & 0.57 & 0.62 & $0.66^{*}$ & 0.02 & 0.17 & $0.59 *$ & $0.16^{*}$ & -0.10 & -0.58 & 0.02 & $0.16^{*}$ \\
\hline GISS-E2-H (p2) & -0.39 & $1.51 *$ & $2.03 *$ & $0.31 *$ & -0.12 & -0.22 & & $0.07 *$ & -0.05 & 0.33 & 0.56 & $0.14 *$ \\
\hline GISS-E2-H (p3) & & & 0.73 & & & -0.01 & & $0.07 *$ & 0.71 & 0.03 & -0.07 & 0.06 \\
\hline GISS-E2-H-CC & & -0.34 & -0.69 & & -0.25 & -0.49 & -0.04 & 0.07 & 0.45 & -0.28 & -0.02 & 0.11 \\
\hline GISS-E2-R (p1) & 1.15 & 0.60 & $1.63^{*}$ & $0.59 *$ & 0.05 & 0.02 & $0.52 *$ & $0.14 *$ & $0.65^{*}$ & 0.50 & 0.46 & 0.10 \\
\hline GISS-E2-R (p2) & & 0.09 & 0.64 & $0.71 *$ & 0.09 & 0.25 & 0.26 & $0.12 *$ & 0.33 & -0.11 & -0.33 & 0.08 \\
\hline GISS-E2-R (p3) & 0.06 & $-1.01 *$ & $1.53^{*}$ & $0.52 *$ & -0.07 & 0.21 & $0.37 *$ & $0.08 *$ & 0.14 & -0.40 & 0.76 & 0.12 \\
\hline GISS-E2-R-CC & -3.21 & 1.63 & -0.46 & & 0.36 & 0.02 & $1.41 *$ & $0.20 *$ & -1.91 & $2.17 *$ & -1.81 & -0.01 \\
\hline HadGEM2-AO & 0.00 & $-11.69 *$ & -1.91 & $-1.36^{*}$ & 3.11 & $-9.80 *$ & 0.33 & -0.54 & -2.58 & -2.80 & -1.03 & $-0.62 *$ \\
\hline HadGEM2-CC & 2.69 & -5.00 & 4.80 & -0.73 & 1.77 & $-8.55^{*}$ & 2.05 & -0.85 & 2.45 & -0.06 & 2.69 & 0.04 \\
\hline HadGEM2-ES & 2.49 & $-3.07 *$ & -0.16 & $-0.85^{*}$ & 1.39 & $-3.09 *$ & -0.06 & $-1.01 *$ & $-1.95^{*}$ & 0.82 & 0.03 & -0.01 \\
\hline INM-CM4.0 & 2.36 & 1.46 & -1.12 & -0.29 & -1.67 & & 1.94 & -0.21 & 2.07 & -1.02 & 0.13 & 0.02 \\
\hline IPSL-CM5A-LR & -0.95 & -0.68 & -0.66 & -0.26 & 0.08 & -0.32 & 0.00 & -0.07 & -0.21 & 0.55 & -0.58 & -0.12 \\
\hline IPSL-CM5A-MR & 1.52 & -0.19 & -3.91 & -0.04 & -0.53 & -0.77 & -0.89 & -0.31 & -1.70 & -0.52 & -0.06 & 0.32 \\
\hline IPSL-CM5B-LR & -2.56 & -1.56 & -0.55 & $-1.13^{*}$ & 0.17 & 0.37 & -0.03 & 0.01 & 0.43 & -2.05 & $-4.55^{*}$ & -0.43 \\
\hline MIROC5 & 4.02 & -1.00 & 2.50 & -0.39 & $5.25^{*}$ & -0.46 & 3.40 & -0.29 & 0.93 & -1.27 & -0.30 & $-0.31 *$ \\
\hline MIROC-ESM & 2.24 & 0.23 & -3.17 & -0.01 & -0.77 & $-3.94 *$ & -3.86 & 0.02 & 2.12 & 1.43 & -2.16 & 0.00 \\
\hline $\begin{array}{l}\text { MIROC-ESM- } \\
\text { CHEM }\end{array}$ & 2.28 & 2.30 & -1.30 & 1.09 & 2.95 & 1.75 & $6.01 *$ & 0.38 & -1.12 & 0.93 & -3.43 & 0.37 \\
\hline MPI-ESM-LR & 0.65 & 0.52 & -0.87 & 0.21 & -1.23 & 2.70 & -1.63 & 0.03 & 0.00 & -0.80 & 1.37 & 0.19 \\
\hline
\end{tabular}


TABLE 4. (Continued)

\begin{tabular}{|c|c|c|c|c|c|c|c|c|c|c|c|c|}
\hline & \multicolumn{12}{|c|}{ Trend (with Sen's slope) } \\
\hline & \multicolumn{4}{|c|}{ Annual } & \multicolumn{4}{|c|}{ Monsoon } & \multicolumn{4}{|c|}{ Winter } \\
\hline & $\begin{array}{c}1911- \\
40\end{array}$ & $\begin{array}{c}1941- \\
70\end{array}$ & $\begin{array}{c}1971- \\
2000\end{array}$ & $\begin{array}{c}1902- \\
2000\end{array}$ & $\begin{array}{c}1911- \\
40\end{array}$ & $\begin{array}{c}1941- \\
70\end{array}$ & $\begin{array}{c}1971- \\
2000\end{array}$ & $\begin{array}{c}1902- \\
2000\end{array}$ & $\begin{array}{c}1911- \\
40\end{array}$ & $\begin{array}{c}1941- \\
70\end{array}$ & $\begin{array}{c}1971- \\
2000\end{array}$ & $\begin{array}{c}1902- \\
2000\end{array}$ \\
\hline MPI-ESM-MR & -3.64 & $-4.27 *$ & 0.19 & -0.20 & -1.86 & $-5.26^{*}$ & 1.43 & 0.15 & 0.33 & -0.37 & -1.56 & 0.16 \\
\hline MRI-CGCM3 & 3.63 & -0.51 & 0.55 & 0.65 & $1.92 *$ & 0.38 & 0.38 & $0.49 *$ & 1.26 & 0.65 & 0.12 & -0.20 \\
\hline NorESM1-M & $9.35 *$ & 5.58 & $-17.19 *$ & -0.27 & $10.28 *$ & 5.87 & $-15.22 *$ & -0.74 & -0.50 & 0.82 & 0.20 & 0.08 \\
\hline NorESM1-ME & 5.19 & -3.48 & 4.08 & 0.09 & 4.33 & -4.94 & 4.67 & 0.60 & 1.76 & -1.61 & -0.79 & 0.13 \\
\hline IMD & -3.44 & -2.04 & 1.09 & $-2.23^{*}$ & -1.26 & -1.13 & -0.05 & $-2.43^{*}$ & 1.92 & -1.10 & 1.66 & -0.20 \\
\hline
\end{tabular}

\section{4) COMPARISON OF SNR}

Table 6 summarizes the SNR values of GCMs and observations. The SNR values (absolute ratio of the linear forced trend and the standard deviation of the residuals) of observations were $0.85,1.02$, and 0.47 , respectively, in annual, monsoon, and winter seasons, which indicate that the climate of WHR has been dominated by the internal variability component during winter as well as in annual scale over the last century. In the monsoon season, both the anthropogenic and the internal variability components have equal relative strength.

In CMIP3, the SNR values varied from 0.04 to 1.14 irrespective to models and seasons. The mean value of the SNR was a maximum for winter (0.37) and a minimum for annual (0.23) season. It is noted that the mean value of SNR (0.33) computed from all GCMs in monsoon season lies between the SNR values of annual (0.23) and winter season (0.37). As the SNR values for most of the models were less than 1 , the model simulations were hence dominated by the interannual variability of the unforced component. Except for HadCM3, none of the models were able to simulate the SNR values greater than 1 during the monsoon season. For HadGEM1, ECHAM4, IPSL-CM4, CSIRO Mk3.5, and GFDL CM2.0 the SNR values were low compared to the observations.

Three GCMs [GISS-E2-R (p2), GISS-E2-H (p1), and GISS-E2-R (p1)] from CMIP5 failed to simulate the observed SNR as they showed unrealistic magnitude, which varied from 1.54 to 1.97 in annual and monsoon. In CMIP5, the majority of the GCMs $(\sim 82 \%)$ had an $\mathrm{SNR}<1$ irrespective of the seasons. The SNR values for all the GCMs in winter season showed good agreement (low $R_{e}$ ) with observation.

\section{c. Ranking of GCMs for overall performance}

The ranking score of GCMs was analyzed for the purpose of differentiating poorly performing and betterperforming models. Figure 3 a shows an example of how the ranking method based on $R_{e}$ was used to rank the 13
GCMs of CMIP3. The final rank for an individual GCM was obtained by summing the ranks of each model evaluation method used and is summarized in Table 7.

In CMIP3, MIROC3.2 (hires) was able to simulate the observed spatial, temporal, and interannual variability of observed rainfall adequately whereas HadGEM1 failed to do so. MIROC3.2 (hires) had an overall rank of 1 followed by the GFDL CM2.0, GFDL CM2.1 and CSIRO Mk3.5 models with ranks 2, 3, and 4, respectively. Similarly, HadGEM1 had an overall rank of 13. By ranking the GCMs according to the different model evaluation method, it was inferred that the most appropriate GCM for the WHR was MIROC3.2 (hires), whereas ECHAM4, HadCM3, and HadGEM1 did not reproduce the observed precipitation characteristics.

Ranking scores of GCMs were more complicated in CMIP5, with MIROC5, CESM1(BGC), INM-CM4.0, GFDL-ESM2G, CCSM4, ACCESS1.0, and GFDL CM3 in the top (ranked 1-6, respectively) and GISS-E2-H (p2), GISS-E2-R (p2), FGOALS-g2, and MRI-CGCM3 were at the bottom (ranked 39-42, respectively). The top-ranked GCMs did not show consistent ranks for individual model evaluation method as the variation in the statistical indices were very small for some methods such as the spatial correlation and annual cycle. A sensitivity test of the ranks was used to discriminate the poorly performing models. CESM1(BGC), NorESM1$\mathrm{M}$, and NorESM1-ME were among the top five GCMs when it came to simulating the mean annual cycle of rainfall and annual cycle of interannual variability. Similarly, EC-EARTH, GISS-E2-R (p3), and CMCC-CMS were among the top $12 \mathrm{GCMs}$ in simulating the observed spatial pattern of monthly, seasonal, and annual rainfall. The 8 GCMs among the top 12 GCMs in simulating the observed trend and SNR included CanESM2, IPSLCM5B-LR, IPSL-CM5A-LR, HadGEM2-ES, MIROC5, ACCESS1.0, INM-CM4.0, and CESM1(BGC). A clusterbased method to find suitable models showed that all the three HadGEM versions, two versions of ACCESS, two versions of NorESM, CESM1, and CCSM4 were grouped 
TABLE 5. Model performance through monthwise and seasonwise spatial correlation coefficient between observation and model during $1902-2000$

\begin{tabular}{|c|c|c|c|c|c|c|c|c|c|c|c|c|c|c|c|}
\hline & Jan & Feb & Mar & Apr & May & Jun & Jul & Aug & Sep & Oct & Nov & Dec & Annual & JJAS & DJF \\
\hline \multicolumn{16}{|l|}{ CMIP3 } \\
\hline BCCR-BCM2.0 & -0.05 & .42 & 0.79 & 0.78 & 0.71 & 0.40 & -0.14 & -0.19 & 0.06 & 0.22 & 0.46 & -0.04 & -0.10 & -0.09 & 0.14 \\
\hline CGCM3.1 (T47) & & & & & & & & & & & & 0.79 & & 0.01 & 0.79 \\
\hline CNRM-CM3 & 0.08 & 0.33 & 0.70 & 0.75 & & 0.61 & & -0.17 & & & -0.26 & & & & 0.12 \\
\hline CSIRO Mk3.0 & 0.87 & 0.87 & 0.25 & -0.38 & & 0.60 & -0.03 & -0.07 & & & & & & 0.01 & 0.84 \\
\hline CSIRO Mk3.5 & & 0.87 & 0.60 & -0.42 & & & & 0.08 & -0.35 & & 0.57 & & & 0.05 & 0.86 \\
\hline GFDL & .77 & 0.88 & 0.90 & 0.80 & 0.56 & 0.56 & -0.04 & -0.12 & 0.17 & -0.46 & 0.61 & 0.57 & & 0.02 & 0.82 \\
\hline GFDL CM2 & & 0.63 & 0.82 & & & & & & & & & & & & \\
\hline ECHAM4 & -0.85 & -0.73 & -0.69 & -0.69 & 0.00 & 0.12 & -0.06 & -0.02 & -0.32 & & & & & & -0.81 \\
\hline & 0.08 & & & & 0.34 & -0.40 & & -0.09 & 0.29 & & & & & 0.09 & 0.05 \\
\hline IPSL-C & 0.55 & 0.49 & & 0.28 & 0.55 & -0.12 & -0.20 & 0.02 & & & 0.7 & & & & 0.61 \\
\hline MIROC3.2(1 & 0.86 & 084 & & & 0.48 & 0.59 & -0.01 & -0.12 & & & & & & & 0.86 \\
\hline $\mathrm{Had}$ & -0.60 & -0.6 & & & & -0.50 & & & -0.38 & & 0.30 & & & & -0.62 \\
\hline HadGEM1 & -0.84 & -0.67 & 0.89 & 0.77 & 0.54 & & -0.04 & 0.08 & & & & & & -0.07 & -0.82 \\
\hline \multicolumn{16}{|l|}{ MIP5 } \\
\hline $\mathrm{ACCE}$ & 0.66 & 0.64 & 0.64 & 0.58 & 0.35 & 0.50 & -0.06 & -0.13 & 0.26 & -0.63 & 0.83 & & & 0.00 & 0.71 \\
\hline ACCES & 0 & 0.14 & 0.65 & 0.6 & 0.43 & -0.20 & -0.17 & & 0.15 & & 0.80 & & & & \\
\hline BCC_C & & & & & & -0.06 & & & & & & & & & 0.16 \\
\hline $\mathrm{BC}$ & & ( & & & 0.7 & 0. & & & -0.34 & & 0.2 & & & & 0.36 \\
\hline $\mathrm{BNL}$ & 0.1 & ( & 0.87 & & 0.50 & 0.56 & -0.05 & -0.13 & 0.26 & 0.37 & 0.1 & & & & 0.27 \\
\hline $\mathrm{CanF}$ & & & & & & & & & & -0 . & & & & & \\
\hline $\mathrm{CC}$ & & & & & & & & & & & & & & & 0.60 \\
\hline & & & & & & & -0.17 & -0.2 & & & 0.7 & & & & 0.64 \\
\hline CES & & 0.8 & & 0 & 0.40 & 0.5 & -0.13 & -0 . & 0.1 & & 0.8 & & & & 0.83 \\
\hline & & & & & & & & & & & & & & & \\
\hline & & & & & & & & & & & & & & & 76 \\
\hline & & & & & & & & -0 . & & & & & & & \\
\hline CSII & 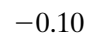 & & & & & -0.03 & -0.01 & -0 & & & & & & & \\
\hline & & & & & & & & & & & & & & & \\
\hline & & & & & & -0.05 & -0 & -0 & 7 & -0 & & & & & .11 \\
\hline & & & & & & & & & & & & & & & \\
\hline & & & & & & & & & & & & & & & \\
\hline & & & & & & & & & & & & & & & \\
\hline & & & & & & & -0.02 & -0.12 & 0.24 & & 2 & & & & 0.28 \\
\hline & & & & & & . & & & & & & & & & \\
\hline & & & & & & & & & & & & & & & \\
\hline GIS & & & & & & 0 & & & -0 & & & & & & .80 \\
\hline & & & & & & 9 & & & & & & & & & 0.79 \\
\hline & & & & & & -0.44 & & & & -0 & & & & & \\
\hline GIS & & & & & & -0.45 & & & & -0 & & & & & \\
\hline & & 0 & & & .05 & -0.43 & 0.16 & 0.24 & -0.25 & -0.60 & 3 & & & .07 & 0.88 \\
\hline & & & & & & -0.44 & & & -0.26 & -0 & & & & & 0.88 \\
\hline & & & & & & & -0.09 & 016 & & -0 & & & & & \\
\hline $\mathrm{Hac}$ & & & & & & & & & 0.22 & -0 & 0.81 & & & & 0.64 \\
\hline 12-ES & & 0.67 & .68 & 0.56 & 47 & 0.51 & -0.08 & -0.16 & 0.24 & -0.42 & 0.82 & 0.66 & -0.17 & -0.02 & 0.65 \\
\hline & & & & & & & & -0.14 & & & -0.42 & & & & \\
\hline & & & & & & -0.31 & -0.02 & -0.12 & & 0.29 & & & & 00 & 0.35 \\
\hline IPSL-CM5A-MR & & & & & & & & & & & -0.01 & & & & \\
\hline IPSL-CM5B-LR & & & & & & -0.37 & -0.15 & -0.12 & -0.20 & -0.26 & 0.20 & 0.07 & -0.06 & -0.15 & 0.23 \\
\hline & & & & & & & -0.10 & -0.21 & & & & & & & 0.88 \\
\hline & & & & & & 0.3 & -0.11 & -0.20 & 0.20 & 47 & -0.68 & & & & 0.24 \\
\hline $\begin{array}{l}\text { MIROC-ESM- } \\
\text { CHEM }\end{array}$ & & 0.62 & & 0.85 & & 0.40 & & & 0.19 & 0.40 & & & & & 0.12 \\
\hline MPI-ESM-LR & & & & & & & & & & & & & & & 0.75 \\
\hline & & & & & & & & & & & & & & & 0.80 \\
\hline MRI-CGCM3 & 0.69 & 0.69 & 0.87 & 0.75 & 0.48 & -0.31 & -0.11 & -0.15 & -0.06 & -0.54 & 0.69 & & & & 0.71 \\
\hline NorESM1-M & & & & & & 0.59 & -0.08 & -0.17 & 0.21 & & 0.01 & -0.50 & -0.14 & -0.02 & 0.05 \\
\hline NorESM1-ME & -0.01 & 0.50 & 0.81 & 0.80 & 0.40 & 0.59 & -0.08 & -0.17 & 0.23 & 0.24 & 0.10 & -0.09 & -0.14 & -0.02 & 0.19 \\
\hline
\end{tabular}


TABLE 6. Model performance through signal-to-noise analysis during 1902-2000.

\begin{tabular}{|c|c|c|c|}
\hline & \multicolumn{3}{|c|}{ SNR values } \\
\hline & Annual & Monsoon & Winter \\
\hline \multicolumn{4}{|l|}{ CMIP3 } \\
\hline BCCR-BCM2.0 & 0.04 & 0.29 & 0.59 \\
\hline CGCM3.1 (T47) & 0.36 & 0.36 & 0.18 \\
\hline CNRM-CM3 & 0.51 & 0.06 & 0.93 \\
\hline CSIRO Mk3.0 & 0.06 & 0.43 & 0.30 \\
\hline CSIRO Mk3.5 & 0.08 & 0.13 & 0.25 \\
\hline GFDL CM2.0 & 0.22 & 0.07 & 0.04 \\
\hline GFDL CM2.1 & 0.13 & 0.55 & 0.41 \\
\hline ECHAM4 & 0.10 & 0.15 & 0.43 \\
\hline INM-CM3.0 & 0.49 & 0.28 & 0.20 \\
\hline IPSL-CM4 & 0.07 & 0.16 & 0.31 \\
\hline MIROC3.2 (hires) & 0.53 & 0.54 & 0.55 \\
\hline HadCM3 & 0.37 & 1.14 & 0.25 \\
\hline HadGEM1 & 0.09 & 0.20 & 0.40 \\
\hline \multicolumn{4}{|l|}{ CMIP5 } \\
\hline ACCESS1.0 & 0.29 & 0.47 & 0.22 \\
\hline ACCESS1.3 & 0.44 & 0.68 & 0.12 \\
\hline BCC_CSM1.1 & 0.02 & 0.53 & 0.15 \\
\hline BCC_CSM1.1(m) & 0.04 & 0.42 & 0.01 \\
\hline BNU-ESM & 0.50 & 0.46 & 0.27 \\
\hline CanESM2 & 0.44 & 0.62 & 0.41 \\
\hline CCSM4 & 0.21 & 0.32 & 0.06 \\
\hline CESM1(BGC) & 0.21 & 0.11 & 0.27 \\
\hline CESM1(CAM5) & 1.26 & 1.06 & 0.74 \\
\hline CMCC-CM & 0.45 & 0.56 & 0.37 \\
\hline CMCC-CMS & 0.11 & 0.61 & 0.30 \\
\hline CNRM-CM5 & 0.10 & 0.00 & 0.06 \\
\hline CSIRO Mk3.6.0 & 0.10 & 0.91 & 0.63 \\
\hline EC-EARTH & 1.26 & 1.62 & 0.21 \\
\hline FGOALS-g2 & 0.98 & 0.69 & 0.32 \\
\hline FIO-ESM & 0.36 & 0.44 & 0.10 \\
\hline GFDL CM3 & 0.04 & 0.26 & 0.22 \\
\hline GFDL-ESM2G & 0.16 & 0.31 & 0.14 \\
\hline GFDL-ESM2M & 0.06 & 0.11 & 0.11 \\
\hline GISS-E2-H (p1) & 1.61 & 1.91 & 0.66 \\
\hline GISS-E2-H (p2) & 0.69 & 0.84 & 0.57 \\
\hline GISS-E2-H (p3) & 1.39 & 0.88 & 0.26 \\
\hline GISS-E2-H-CC & 0.89 & 0.34 & 0.20 \\
\hline GISS-E2-R (p1) & 1.66 & 1.93 & 0.42 \\
\hline GISS-E2-R (p2) & 1.97 & 1.54 & 0.32 \\
\hline GISS-E2-R (p3) & 1.45 & 1.03 & 0.61 \\
\hline GISS-E2-R-CC & 0.62 & 0.99 & 0.02 \\
\hline HadGEM2-AO & 0.81 & 0.43 & 0.73 \\
\hline HadGEM2-CC & 0.44 & 0.66 & 0.05 \\
\hline HadGEM2-ES & 1.11 & 1.50 & 0.02 \\
\hline INM-CM4.0 & 0.15 & 0.17 & 0.03 \\
\hline IPSL-CM5A-LR & 0.31 & 0.12 & 0.22 \\
\hline IPSL-CM5A-MR & 0.03 & 0.36 & 0.34 \\
\hline IPSL-CM5B-LR & 0.72 & 0.02 & 0.39 \\
\hline MIROC5 & 0.32 & 0.22 & 0.67 \\
\hline MIROC-ESM & 0.01 & 0.02 & 0.00 \\
\hline $\begin{array}{l}\text { MIROC-ESM- } \\
\text { CHEM }\end{array}$ & 0.54 & 0.29 & 0.46 \\
\hline MPI-ESM-LR & 0.23 & 0.04 & 0.36 \\
\hline MPI-ESM-MR & 0.17 & 0.19 & 0.26 \\
\hline MRI-CGCM3 & 0.59 & 0.87 & 0.36 \\
\hline
\end{tabular}

TABLE 6. (Continued)

\begin{tabular}{lccc}
\hline \hline & \multicolumn{3}{c}{ SNR values } \\
\cline { 2 - 4 } & Annual & Monsoon & Winter \\
\hline NorESM1-M & 0.09 & 0.30 & 0.09 \\
NorESM1-ME & 0.03 & 0.25 & 0.15 \\
IMD & 0.85 & 1.02 & 0.47 \\
\hline
\end{tabular}

separately to better understand the precipitation variation, climatology, and the annual cycle over the Himalayan region (Palazzi et al. 2015).

In the present study, the majority of stations are at lower elevations, while a coarse gridcell GCM would exhibit precipitation characteristics of the high-elevation topography within that cell. Contrastingly, a finer-scale GCM would more accurately sample regional topography and better simulate orographic effects. Hence, the impact of model resolution in simulating rainfall over the WHR was also assessed in this study. The rainfall patterns simulated by CMIP3 and CMIP5 GCMs showed that the model evaluation methods (like spatial correlation in different season and trend analysis) were not sensitive to the horizontal resolution of the models (i.e., the higher resolution of the models did not lead to improvements in simulating precipitation). The GCMs with the highest resolution were ECHAM4 in CMIP3 and CCSM4 in CMIP5 (see Tables S3 and S4 of the supplemental material), but the overall rank of both GCMs was lower than most of the GCMs in their respective CMIP project.

\section{d. Sensitivity analysis of ranks}

Figure $3 \mathrm{~b}$ shows the sensitivity test for the ranking of CMIP3 GCMs under different model evaluation methods through box plots. Each box plot shows the variation in overall rankings of a GCM after exclusion or inclusion of different model evaluation method individually. The overall ranking of GCMs like MIROC3.2 (hires), GFDL CM2.1, GFDL CM2.0, CSIRO Mk3.5, and HadGEM1 retained their original rank irrespective of exclusion or inclusion of a specific model evaluation method. The standard deviation in the overall ranking for INM-CM3.0, HadCM3, CGCM3.1 (T47), and CSIRO Mk3.0 was more as compared to other GCMs. Figure $3 \mathrm{c}$ shows the sensitivity test of rankings for the CMIP5 GCMs, where CCSM4, CESM1(BGC), FGOALS-g2, FIO-ESM, GISS-E2-H (p1), GISS-E2-H (p2), INM-CM4.0, MIROC5, MPI-ESM-MR, and MRI-CGCM3 showed that their overall ranks did not vary more than one to three standard deviations after including or removing a particular model evaluation method. The ranking obtained by these GCMs was 
a.

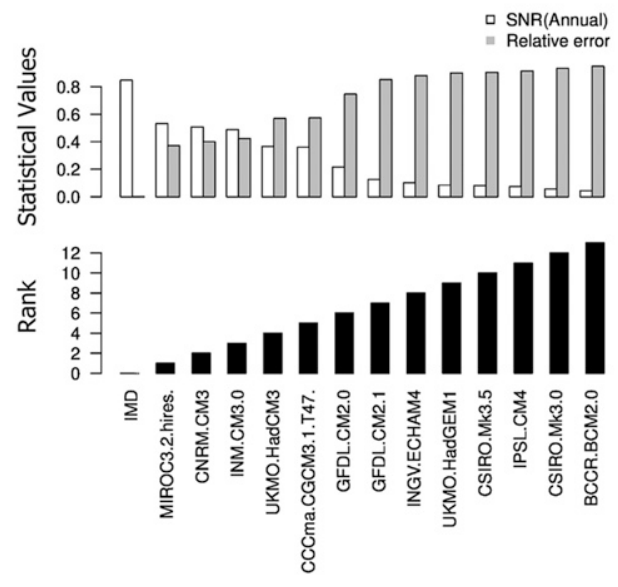

b.

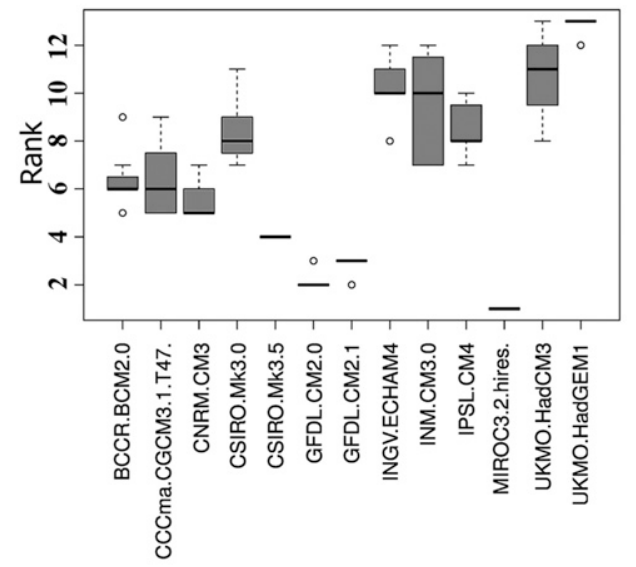

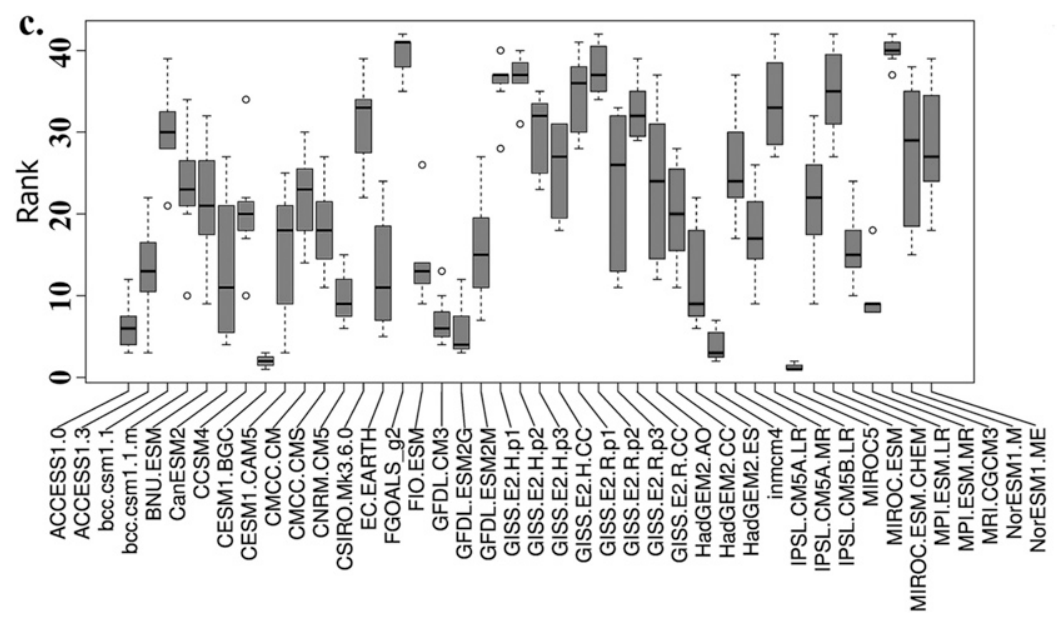

d.

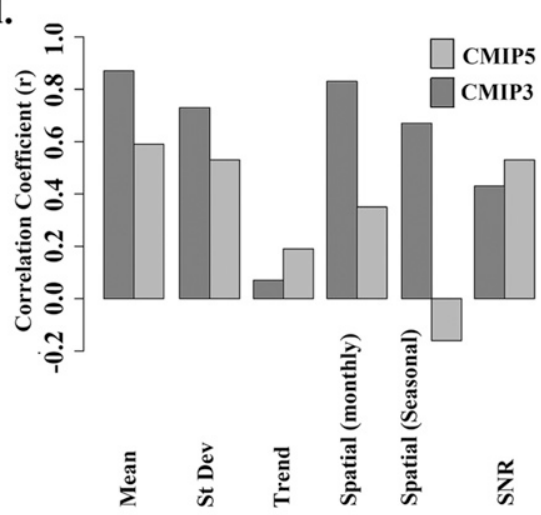

Model evaluation methods

FIG. 3. (a) An example of ranking 13 GCMs from CMIP3 based on $R_{e}$ of SNR values. (b) Sensitivity of final ranks (overall rank) for each CMIP3 GCM was examined by comparing overall ranking (final ranks calculated through all the model evaluation method) and that obtained after removal or inclusion of individual model evaluation method one by one. (c) As in (b), but for CMIP5 GCMs. (d) Correlation between overall and individual method of model evaluation.

more robust than other GCMs of CMIP5 using multievaluation method than a single method.

Figure $3 \mathrm{~d}$ shows how the overall ranks of GCMs varied with ranks obtained through different model evaluation methods, based on the correlation coefficient between overall ranks obtained by different models and ranks obtained through individual method. The model evaluation methods based on the mean annual cycle, the annual cycle of standard deviation, the spatial correlation for the monthly distribution of rainfall, and the SNR produced rankings close to the overall ranking, while the trend analysis method and spatial correlation for seasonal rainfall (only CMIP5) method produced a totally different ranking. This implies that trend analysis and spatial correlation analysis at seasonal scale were not the robust methods of examining the performance of GCMs over the WHR.

\section{Discussion}

\section{a. Observed rainfall analysis}

The WHR was subject to a significant negative trend in the annual and monsoon rainfall during 1902-2005. The possible causes of such negative trends were not investigated directly in the present study rather several studies, which have explained the causes of such negative trends of rainfall were cited here. Kumar and Jaswal (2016) reported that the cause of significant negative trends of observed monsoon rainfall during the last three decades was most probably due to the weakening of teleconnection between monsoon rainfall with North Atlantic Oscillation (NAO) index as well as Southern Oscillation index (SOI). There was a weak decadal running correlation between monsoon precipitation and the NAO as well as monsoon precipitation and the SOI 
TABLE 7. Ranking of GCMs for different methods of model evaluation and overall rank of GCMs.

\begin{tabular}{|c|c|c|c|c|c|c|c|c|}
\hline & \multicolumn{2}{|c|}{ Annual cycle } & \multirow[b]{2}{*}{ Trend } & \multicolumn{2}{|c|}{ Spatial correlation } & \multirow[b]{2}{*}{ SNR } & \multirow{2}{*}{$\begin{array}{c}\text { Total sum } \\
\text { of ranks }\end{array}$} & \multirow{2}{*}{$\begin{array}{c}\text { Overall } \\
\text { rank }\end{array}$} \\
\hline & Mean & Std dev & & Monthwise & Seasonwise & & & \\
\hline \multicolumn{9}{|l|}{ CMIP3 } \\
\hline BCCR-BCM2.0 & 5 & 7 & 6 & 9 & 10 & 7 & 44 & 6 \\
\hline CGCM3.1 (T47) & 6 & 4 & 13 & 3 & 6 & 12 & 44 & 6 \\
\hline CNRM-CM3 & 4 & 12 & 8 & 8 & 7 & 3 & 42 & 5 \\
\hline CSIRO Mk3.0 & 9 & 8 & 12 & 7 & 5 & 7 & 48 & 8 \\
\hline CSIRO Mk3.5 & 8 & 6 & 10 & 4 & 2 & 4 & 34 & 4 \\
\hline GFDL CM2.0 & 2 & 3 & 4 & 2 & 3 & 7 & 21 & 2 \\
\hline GFDL CM2.1 & 1 & 1 & 5 & 5 & 9 & 5 & 26 & 3 \\
\hline ECHAM4 & 12 & 10 & 1 & 13 & 11 & 6 & 53 & 11 \\
\hline INM-CM3.0 & 13 & 13 & 3 & 6 & 4 & 13 & 52 & 10 \\
\hline IPSL-CM4 & 7 & 5 & 11 & 10 & 8 & 7 & 48 & 8 \\
\hline MIROC3.2 (hires) & 3 & 2 & 2 & 1 & 1 & 1 & 10 & 1 \\
\hline HadCM3 & 9 & 8 & 9 & 12 & 13 & 2 & 53 & 11 \\
\hline HadGEM1 & 11 & 11 & 6 & 11 & 11 & 11 & 61 & 13 \\
\hline \multicolumn{9}{|l|}{ CMIP5 } \\
\hline ACCESS1.0 & 10 & 9 & 7 & 27 & 34 & 10 & 97 & 5 \\
\hline ACCESS1.3 & 19 & 12 & 20 & 42 & 17 & 2 & 112 & 9 \\
\hline BCC_CSM1.1 & 31 & 28 & 21 & 39 & 12 & 15 & 146 & 31 \\
\hline BCC_CSM1.1(m) & 24 & 8 & 31 & 40 & 8 & 20 & 131 & 24 \\
\hline BNU-ESM & 21 & 6 & 41 & 13 & 14 & 32 & 127 & 21 \\
\hline CanESM2 & 26 & 30 & 1 & 38 & 17 & 1 & 113 & 11 \\
\hline CCSM4 & 1 & 19 & 21 & 33 & 23 & 27 & 124 & 19 \\
\hline CESM1(BGC) & 2 & 3 & 12 & 26 & 19 & 9 & 71 & 2 \\
\hline CESM1(CAM5) & 3 & 11 & 39 & 6 & 16 & 39 & 114 & 13 \\
\hline CMCC-CM & 25 & 17 & 33 & 15 & 5 & 34 & 129 & 23 \\
\hline CMCC-CMS & 27 & 23 & 34 & 10 & 9 & 19 & 122 & 18 \\
\hline CNRM-CM5 & 15 & 18 & 12 & 31 & 14 & 17 & 107 & 7 \\
\hline CSIRO Mk3.6.0 & 41 & 39 & 5 & 21 & 21 & 22 & 149 & 33 \\
\hline EC-EARTH & 12 & 29 & 28 & 3 & 10 & 31 & 113 & 11 \\
\hline FGOALS-g2 & 30 & 27 & 37 & 14 & 30 & 35 & 173 & 41 \\
\hline FIO-ESM & 23 & 21 & 6 & 17 & 23 & 25 & 115 & 14 \\
\hline GFDL CM3 & 17 & 7 & 27 & 2 & 28 & 17 & 98 & 6 \\
\hline GFDL-ESM2G & 14 & 1 & 29 & 7 & 31 & 12 & 94 & 4 \\
\hline GFDL-ESM2M & 16 & 1 & 34 & 11 & 33 & 23 & 118 & 15 \\
\hline GISS-E2-H (p1) & 33 & 36 & 18 & 24 & 7 & 42 & 160 & 37 \\
\hline GISS-E2-H (p2) & 36 & 36 & 15 & 25 & 12 & 37 & 161 & 39 \\
\hline GISS-E2-H (p3) & 35 & 36 & 14 & 21 & 6 & 36 & 148 & 32 \\
\hline GISS-E2-H-CC & 34 & 34 & 9 & 20 & 10 & 30 & 137 & 27 \\
\hline GISS-E2-R (p1) & 40 & 40 & 19 & 16 & 3 & 41 & 159 & 36 \\
\hline GISS-E2-R (p2) & 42 & 40 & 23 & 18 & 4 & 38 & 165 & 40 \\
\hline GISS-E2-R (p3) & 37 & 40 & 3 & 12 & 1 & 39 & 132 & 26 \\
\hline GISS-E2-R-CC & 37 & 35 & 32 & 19 & 2 & 29 & 154 & 34 \\
\hline HadGEM2-AO & 9 & 12 & 38 & 30 & 40 & 2 & 131 & 24 \\
\hline HadGEM2-CC & 12 & 12 & 26 & 32 & 36 & 7 & 125 & 20 \\
\hline HadGEM2-ES & 11 & 25 & 9 & 28 & 35 & 4 & 112 & 9 \\
\hline INM-CM4.0 & 21 & 21 & 8 & 5 & 20 & 11 & 86 & 3 \\
\hline IPSL-CM5A-LR & 29 & 31 & 4 & 34 & 31 & 8 & 137 & 27 \\
\hline IPSL-CM5A-MR & 28 & 26 & 16 & 9 & 25 & 16 & 120 & 17 \\
\hline IPSL-CM5B-LR & 39 & 33 & 2 & 41 & 36 & 4 & 155 & 35 \\
\hline MIROC5 & 7 & 16 & 11 & 1 & 28 & 6 & 69 & 1 \\
\hline MIROC-ESM & 8 & 12 & 30 & 23 & 41 & 14 & 128 & 22 \\
\hline $\begin{array}{l}\text { MIROC-ESM- } \\
\text { CHEM }\end{array}$ & 6 & 9 & 42 & 29 & 41 & 33 & 160 & 37 \\
\hline MPI-ESM-LR & 17 & 24 & 16 & 8 & 25 & 28 & 118 & 15 \\
\hline MPI-ESM-MR & 20 & 20 & 23 & 4 & 22 & 20 & 109 & 8 \\
\hline MRI-CGCM3 & 32 & 31 & 23 & 35 & 27 & 26 & 174 & 42 \\
\hline NorESM1-M & 5 & 4 & 40 & 37 & 39 & 13 & 138 & 29 \\
\hline NorESM1-ME & 4 & 5 & 36 & 36 & 36 & 24 & 141 & 30 \\
\hline
\end{tabular}


particularly during the last three decades of 1857-2006. Another possible reason for decreasing precipitation over the Himalayas may be a decrease in the transportation of water vapor from the tropical Indian Ocean to the Himalayas as a result of a decreasing thermal contrast between the Tibetan Plateau and Indian Ocean (Duan et al. 2006). There are also several other explanations for the change in rainfall pattern over the WHR, such as the alternation in the land use and land cover, urbanization, deforestation, and other anthropogenic factors. After the independence of India in 1947, the central Himalayas faced faster deforestation for economic development. During the 1960s and 1970s, this region was subject to exploitation against the vast area of forest cover (Nautiyal and Babor 1985). Increases in aerosol content may also have caused the reduction of monsoon rainfall over India through solar dimming effect (SDE), resulting in a spindown of the regional monsoon circulation (Ramanathan et al. 2005). Salzmann et al. (2014) also reported that the observed post-1950 negative trend of Indian monsoon rainfall could be attributed to the significant impact of aerosol on Indian summer monsoon circulation.

\section{b. Model evaluation and ranking}

Analysis of mean annual cycle showed a dry bias of monsoon rainfall in most of the GCMs. Saha et al. (2014) reported that the dry bias of Indian monsoon rainfall in the CMIP5 GCMs is due to their underestimation of surface warming over the southern Indian Ocean (SIO), which may have caused the weakening of the northsouth SST gradient, finally resulting in a weakening of the Hadley circulation. During November and December, the biases in the GCMs were mostly positive. A similar behavior was reported by Palazzi et al. (2015) over the Himalayan region, which strongly supports the results of the present study. A possible cause of this positive bias in the model during the winter months may be the GCM's inabilities in representing local- and regional-scale processes due to the coarser resolutions of GCMs and inadequate parameterization (Lee et al. 2010; Su et al. 2013). The study by Pal et al. (2007), using the RCM RegCM3, also reported similar results where the winter precipitation over WHR overestimated the observation (Dimri 2012). Some other studies also reported that the GCMs have a peculiar nature of simulating more than the observed seasonal rainfall over the complex topographic regions of the Andes, the Sierra Madre, and the Tibetan Plateau (Lee et al. 2010; Su et al. 2013). It is found that the gross features of the observed annual cycle (mean and interannual variability) were better simulated by the models of CMIP5 compared to CMIP3 because CMIP5 models used improved physical parameterization schemes to represent the clouds and radiation processes in addition to improved mean resolution (Dolinar et al. 2015). Kusunoki and Arakawa (2015) reported that the adoption of flux adjustment into a model might produce large errors in some of the fluxes between atmosphere and ocean. Some of the CMIP3 models used flux adjustment, but flux adjustment was completely excluded from CMIP5, which possibly gave a reduction in various biases and an improvement of physical processes in the models.

Based on trend analysis, it is noticed that about $71 \%$ CMIP5 GCMs failed to simulate the observed negative trend of monsoon precipitation during the period 19712000. Saha et al. (2014) reported that a majority of CMIP5 GCMs ( $\sim 78 \%)$ failed to simulate the post-1950 negative trend of monsoon rainfall over the Indian subcontinent because CMIP5 GCMs failed to simulate the large-scale changes, for example, weakening of monsoon rainfall associated with the warming of the southern Indian Ocean and strengthening of cyclonic formation in the tropical western Pacific Ocean. It was revealed that approximately $65 \%$ of CMIP5 GCMs were unable to reproduce the observed long-term rainfall trend while approximately $50 \%$ of GCMs failed in different short-term periods. Why GCMs were not able to reproduce the observed trend adequately has been discussed by several studies. For example, aerosol and other anthropogenic forcings may influence the estimated trends of GCMs (Ramesh and Goswami 2014), which need to be investigated properly. It is quite difficult to quantify the various aerosol effects on Indian summer monsoon rainfall and circulation pattern either from modeling or observational studies alone (Sanap and Pandithurai 2015). The IPCC Fifth Assessment Report (AR5) also reported that there was a low-moderate understanding of aerosol-cloud-precipitation interaction among the scientific community and these interactions were not well represented in the climate models.

Almost all the GCMs in CMIP3 and CMIP5 were able to reproduce the observed spatial rainfall patterns quite well during the winter and premonsoon seasons while they failed during the monsoon and annual scale. A strong pattern correlation between the observation and GCMs were found during the boreal winter while it was weak during the monsoon season (Srinivasan et al. 1995) over the tropical monsoon region. In general, GCMs are unable to represent the regional forcing such as complex topography, orographic lifting, etc. (Palazzi et al. 2015) properly, causing this weak relationship. A similar conclusion was also drawn by Kripalani et al. (2007) over the Western Ghats and the Himalayan region. The higher spatial correlations during winter were dominated by orographically enhanced precipitation due to western 
disturbances, suggesting that the lack of correlation in summer is also associated with the GCM's inability to represent the convective processes that dominate during the monsoon. Furthermore, determining a GCM's performance based on its ability to represent spatial patterns of convection over such a small region like WHR is challenging given convection's spatiotemporal complexity. Even in convection permitting models, it is improbable that precipitation would be simulated skillfully over such a small region given there are many other unresolved influences on convection. Ranks based on spatial correlation in different seasons had little bearing on the overall rank of different GCMs, this is one of the limitations of spatial correlation as a GCM metric for this particular region, which is topographic complex and poorly sampled.

The present study revealed that, some coarser-resolution GCMs showed better skills compared to the GCMs with high resolution (Tables S3 and S4 of the supplemental material) over the WHR whose climate is mainly driven by large-scale ocean-atmosphere circulations like monsoon in wet season (i.e., monsoon) and western disturbances in the dry season (i.e., winter). Similar results were also reported by Boyle and Klein (2010) and Bacmeister et al. (2014), who mentioned that the systematic improvements in highresolution GCMs are not always certain, as the effect of horizontal resolution alone may not improve the biases in the large-scale mean seasonal aspects of the simulated climatology. The sensitivity of the model resolution on rainfall was also documented in some of the previous studies. Song and Zhou (2014) have highlighted that the CMIP3- and CMIP5-based simulated rainfall in the monsoon season over East Asia is not sensitive to the horizontal resolutions of the models; in addition, Chan et al. (2013) and Boyle and Klein (2010) also reported that the higher resolution of models does not necessarily lead to improvements in precipitation simulation.

The overall performance of GCMs indicated that MIROC3.2 (hires) was the top-ranked model in the CMIP3 over the WHR. The similar better performance of the MIROC3.2 (hires) GCM was also reported by Das et al. (2012) over the Gangetic West Bengal and its neighboring region in their earlier study. The other studies by Raju and Kumar $(2014,2015)$ provided a common set of CMIP3 GCMs, namely, GFDL CM2.0, MIROC3.2 (hires), GFDL CM2.1, and HadCM3, having better skills in simulating the hydrological regime over different parts of India. Another study by Anandhi and Nanjundiah (2015) showed that the GCMs like CSIRO Mk3.5, CNRM-CM3, and MIROC3.2 (hires) were ranked at 3,6 , and 9 , respectively, out of 19 CMIP3 models in simulating the observed annual rainfall over the hilly regions of India including the WHR. Das et al. (2016b) also reported some better-performing models from CMIP5 [CESM1(BGC), INM-CM4.0, and GFDLESM2G] over the Chilka lagoon of India, which occupied second, third, and fourth rank respectively in this study.

Based on the sensitivity analysis on model ranking indicates that ranks of some GCMs were not highly dependent on the method of model evaluation as the position of ranks for the top- and bottom-ranked GCMs were not changed significantly after adding or removing a specific method of model evaluation. However, in case of other models (models lie between the top and bottom ranked), the position of ranks change after adding or removing a specific method in the evaluation process, indicating that the model should be evaluated through multiple methods rather than a single method. The selected top-ranked GCMs can be used to develop more reliable climate change information using statistical downscaling techniques, which can be used as an input for impact models like crop simulation or hydrological models over subregional and local scale for decisionmaking and/or policy issue.

Apart from providing useful information to improve the skill to simulate observed climate, the GCM evaluation is also useful to select suitable model for downscaling work to overcome the scale discrepancy between climate change scenario and resolution required for impact research $(\mathrm{Fu}$ et al. 2013). To this day, GCMs are not adequate to represent the local scale effects of topography and aerosol on precipitation (Bollasina et al. 2011). Hence, it was difficult to predict changes in precipitation patterns over the plains as well as mountains (Beniston 2003) using GCMs simulations. For example, the study by Hasson et al. (2013) reported that the CMIP3 GCMs failed to simulate the realistic rainfall pattern over the Tibetan Plateau. Similarly, inaccurate representation of the KarakoramHimalayan orography in CMIP3 and CMIP5 models may lead to the biases in the Indian summer monsoon precipitation (Boos and Hurley 2013). On the other hand, Sperber et al. (2013) reported that the CMIP5 models have shown improving abilities to simulate realistic rainfall patterns adjacent to the foothills of the Himalayas compared to the CMIP3 models. In general, a model's inability to resolve local topography in addition to other issues regarding model physics as well as model initialization may play a crucial role to influence the performance of GCMs over different parts of the globe.

\section{Conclusions}

The present work has been concluded with the following major findings:

1) Station data indicated significant negative trends of annual and monsoon precipitation over the western Himalayan region during 1902-2005. 
2) The majority of the CMIP3 and CMIP5 GCMs failed to reproduce the gross or mean observed precipitation climatology in term of mean annual cycles, spatial patterns, and short- and long-term trends. As compared to CMIP3 GCMs, CMIP5 GCMs were able to reproduce the pattern and magnitude of mean and interannual variability in a more realistic way.

3) MIROC3.2 (hires), GFDL CM2.0, and GFDL CM2.1 from CMIP3 and MIROC5, CESM1(BGC), and INM-CM4.0 from CMIP5 were ranked as the most skillful models. In addition, the horizontal resolution of the models did not lead to improvements in simulating precipitation over the study region.

4) Top- and bottom-ranked GCMs were not highly dependent on the method of model evaluation; however, the ranks of GCMs within the middle of the ranking list were depended on the method of evaluation. It is found that multiple methods of model evaluation are essential instead of a single method to put more confidence in the results.

Acknowledgments. The authors sincerely thank the Norway Research Council for funding the Indo-Norway international research project INDICE through which the present work has been carried out. The authors acknowledged the assistance and support provided by the members of Climate Simulation Lab, Bidhan Chandra Krishi Viswavidyalaya (BCKV), West Bengal, and Norwegian Water Resources and Energy Directorate (NVE) through which the fund is channelized. Thanks from the authors go to NCC, Indian Meteorological Department (IMD), Pune, and KNMI for making data available for this study. The authors thank Dr. D. S. Pai, IMD, Pune, for providing valuable information (personal communication) on the IMD gridded data (IMD4). All the authors thank three anonymous reviewers for their extensive effort in providing valuable comments and suggestions to improve the quality of the present work.

\section{REFERENCES}

Akhter, J., L. Das, and A. Deb, 2016: CMIP5 ensemble-based spatial rainfall projection over homogeneous zones of India. Climate Dyn., doi:10.1007/s00382-016-3409-8, in press.

$\longrightarrow,-$ J. K. Meher, and A. Deb, 2017: Uncertainties and time of emergence of multi-model precipitation projection over homogeneous zones of India. Climate Dyn., doi:10.1007/ s00382-017-3847-y, in press.

Anandhi, A., and R. S. Nanjundiah, 2015: Performance evaluation of AR4 climate models in simulating daily precipitation over the Indian region using skill scores. Theor. Appl. Climatol., 119, 551-566, doi:10.1007/s00704-013-1043-5.

Andermann, C., S. Bonnet, and R. Gloaguen, 2011: Evaluation of precipitation data sets along the Himalayan front. Geochem. Geophys. Geosyst., 12, Q07023, doi:10.1029/2011GC003513.
Annamalai, H., K. Hamilton, and K. R. Sperber, 2007: The South Asian summer monsoon and its relationship with ENSO in the IPCC AR4 simulations. J. Climate, 20, 1071-1092, doi:10.1175/ JCLI4035.1.

Arora, M., P. Singh, N. K. Goel, and R. D. Singh, 2006: Spatial distribution and seasonal variability of rainfall in a mountainous basin in the Himalayan region. Water Resour. Manage., 20, 489508, doi:10.1007/s11269-006-8773-4.

Azadi, M., U. C. Mohanty, O. P. Madan, and B. Padmanabhamurty, 2002: Prediction of precipitation associated with a western disturbance using a high-resolution regional model: Role of parameterisation of physical processes. Meteor. Appl., 9, 317-326, doi:10.1017/S1350482702003055.

Bacmeister, J. T., M. Wehner, R. B. Neale, A. Gettelman, C. Hannay, P. Lauritzen, and J. Caron, 2014: Exploratory high-resolution climate simulations using the Community Atmosphere Model (CAM). J. Climate, 27, 3073-3099, doi:10.1175/JCLI-D-13-00387.1.

Baniya, C. B., H. Rai, and D. K. Upreti, 2013: Terricolous lichens in Himalayas: Patterns of species richness along elevation gradient. Terricolous Lichens in India, H. Rai and D. Upreti, Eds., Springer, 33-52, doi:10.1007/978-1-4614-8736-4_3.

Barros, A. P., and T. J. Lang, 2003: Monitoring the monsoon in the Himalayas: Observations in central Nepal, June 2001. Mon. Wea. Rev., 131, 1408-1427, doi:10.1175/1520-0493(2003)131<1408: MTMITH $>2.0 . \mathrm{CO} ; 2$.

— S. Chiao, T. J. Lang, D. Burbank, and J. Putkonen, 2006: From weather to climate-Seasonal and interannual variability of storms and implications for erosion processes in the Himalaya. Special Paper 398: Tectonics, Climate, and Landscape Evolution, 17-38, doi:10.1130/s2006.2398(02).

Basistha, A., D. S. Arya, and N. K. Goel, 2008: Spatial distribution of rainfall in Indian Himalayas-A case study of Uttarakhand region. Water Resour. Manage., 22, 1325-1346, doi:10.1007/ s11269-007-9228-2.

,$- \ldots$, and -2009 : Analysis of historical changes in rainfall in the Indian Himalayas. Int. J. Climatol., 29, 555-572, doi:10.1002/joc.1706.

Benestad, R. E., A. Mezghani, and K. M. Parding, 2014: esd for Mac \& Linux/esd for Windows, version 17. figshare. [Available online at http://figshare.com/articles/esd_for_Mac_amp_ Linux/1160493.]

Beniston, M., 2003: Climatic change in mountain regions: A review of possible impacts. Global Climate Variability and Change in High Elevation Regions: Past, Present \& Future, H. F. Diaz, Ed., Springer, 5-31, doi:10.1007/978-94-015-1252-7_2.

Bhatt, B. C., and K. Nakamura, 2005: Characteristics of monsoon rainfall around the Himalayas revealed by TRMM Precipitation Radar. Mon. Wea. Rev., 133, 149-165, doi:10.1175/ MWR-2846.1.

Bhutiyani, M. R., V. S. Kale, and N. J. Pawar, 2007: Long-term trends in maximum, minimum and mean annual air temperatures across the northwestern Himalaya during the twentieth century. Climatic Change, 85, 159-177, doi:10.1007/ s10584-006-9196-1.

$\longrightarrow,-$, and ——, 2009: Climate change and the precipitation variations in the northwestern Himalaya: 1866-2006. Int. J. Climatol., 30, 535-548, doi:10.1002/joc.1920.

Blázquez, J., and M. N. Nuñez, 2013: Performance of a high resolution global model over southern South America. Int. J. Climatol., 33, 904-919, doi:10.1002/joc.3478.

Bollasina, M. A., Y. Ming, and V. Ramaswamy, 2011: Anthropogenic aerosols and the weakening of the South Asian 
summer monsoon. Science, 334, 502-505, doi:10.1126/ science.1204994.

Bookhagen, B., and D. W. Burbank, 2010: Toward a complete Himalayan hydrological budget: Spatiotemporal distribution of snowmelt and rainfall and their impact on river discharge. J. Geophys. Res., 115, F03019, doi:10.1029/2009JF001426.

Boos, W. R., and J. V. Hurley, 2013: Thermodynamic bias in the multimodel mean boreal summer monsoon. J. Climate, 26, 2279-2287, doi:10.1175/JCLI-D-12-00493.1.

Boyle, J., and S. A. Klein, 2010: Impact of model horizontal resolution on climate model forecasts of tropical precipitation and diabatic heating for the TWP-ICE period. J. Geophys. Res., 115, D23113, doi:10.1029/2010JD014262.

Chan, S. C., E. J. Kendon, H. J. Fowler, S. Blenkinsop, C. A. Ferro, and D. B. Stephenson, 2013: Does increasing the spatial resolution of a regional climate model improve the simulated daily precipitation? Climate Dyn., 41, 1475-1495, doi:10.1007/s00382-012-1568-9.

Charles, S. P., F. Chiew, and H. Zeng, 2016: Climate change and water in South Asia-Overview and literature review. CSIRO Sustainable Development Investment Portfolio Project Rep., $36 \mathrm{pp}$. [Available online at https://publications.csiro.au/rpr/ download?pid = csiro:EP156957\&dsid=DS3.]

Das, L., and D. Lohar, 2005: Construction of climate change scenarios for a tropical monsoon region. Climate Res., 30, 39-52, doi:10.3354/cr030039.

_ _ J. Annan, J. Hargreaves, and S. Emori, 2012: Improvements over three generations of climate model simulations for eastern India. Climate Res., 51, 201-216, doi:10.3354/cr01064.

— - M. Dutta, J. K. Meher, and J. Akhter, 2016a: Temperature Change Scenarios over the Chilika Lagoon of India during 1901-2100. J. Climate Change, 2, 1-14, doi:10.3233/JCC-160001.

_ J. K. Meher, and M. Dutta, 2016b: Construction of rainfall change scenarios over the Chilka Lagoon in India. Atmos. Res., 182, 36-45, doi:10.1016/j.atmosres.2016.07.013.

_- M. Dutta, A. Mezghani, and R. E. Benestad, 2017: Use of observed temperature statistics in ranking CMIP5 model performance over the Western Himalayan Region of India. Int. J. Climatol., doi:10.1002/joc.5193.

Deser, C., A. Phillips, V. Bourdette, and H. Teng, 2012: Uncertainty in climate change projections: The role of internal variability. Climate Dyn., 38, 527-546, doi:10.1007/s00382-010-0977-x.

Dimri, A. P., 2012: Atmospheric water budget over the western Himalayas in a regional climate model. J. Earth Syst. Sci., 121, 963-973, doi:10.1007/s12040-012-0204-8.

__ , and A. Ganju, 2007: Wintertime seasonal scale simulation over western Himalaya using RegCM3. Pure Appl. Geophys., 164, 1733-1746, doi:10.1007/s00024-007-0239-y.

— western Himalayas. Climatic Change, 111, 775-800, doi:10.1007/ s10584-011-0201-y.

- D. Niyogi, A. P. Barros, J. Ridley, U. C. Mohanty, T. Yasunari, and D. R. Sikka, 2015: Western disturbances: A review. Rev. Geophys., 53, 225-246, doi:10.1002/2014RG000460.

_ - T. Yasunari, B. S. Kotlia, U. C. Mohanty, and D. R. Sikka, 2016: Indian winter monsoon: Present and past. Earth-Sci. Rev., 163, 297-322, doi:10.1016/j.earscirev.2016.10.008.

Dolinar, E. K., X. Dong, B. Xi, J. H. Jiang, and H. Su, 2015: Evaluation of CMIP5 simulated clouds and TOA radiation budgets using NASA satellite observations. Climate Dyn., 44, 2229-2247, doi:10.1007/s00382-014-2158-9.

Duan, K., T. Yao, and L. G. Thompson, 2006: Response of monsoon precipitation in the Himalayas to global warming. J. Geophys. Res., 111, D19110, doi:10.1029/2006JD007084.
Duncan, J. M., E. M. Biggs, J. Dash, and P. M. Atkinson, 2013: Spatio-temporal trends in precipitation and their implications for water resources management in climate-sensitive Nepal. Appl. Geophys., 43, 138-146.

Flato, G. M., 2011: Earth system models: An overview. Wiley Interdiscip Rev.: Climate Change, 2, 783-800, doi:10.1002/ wcc. 148

Fontaine, B., P. Roucou, and P. A. Monerie, 2011: Changes in the African monsoon region at medium-term time horizon using 12 AR4 coupled models under the A1b emissions scenario. Atmos. Sci. Lett., 12, 83-88, doi:10.1002/asl.321.

Fu, G., Z. Liu, S. P. Charles, Z. Xu, and Z. Yao, 2013: A scorebased method for assessing the performance of GCMs: A case study of southeastern Australia. J. Geophys. Res. Atmos., 118, 4154-4167, doi:10.1002/jgrd.50269.

Gautam, M. R., G. R. Timilsina, and K. Acharya, 2013: Climate change in the Himalayas: Current state of knowledge. World Bank Policy Research Working Paper 6516, 64 pp., doi:10.1596/1813-9450-6516.

Giorgi, F., X. Bi, and J. Pal, 2004: Mean, interannual variability and trends in a regional climate change experiment over Europe. I. Present-day climate (1961-1990). Climate Dyn., 22, 733-756, doi:10.1007/s00382-004-0409-x.

Guhathakurta, P., and M. Rajeevan, 2008: Trends in the rainfall pattern over India. Int. J. Climatol., 28, 1453-1469, doi:10.1002/joc. 1640

Hasson, S., V. Lucarini, and S. Pascale, 2013: Hydrological cycle over south and southeast Asian river basins as simulated by PCMDI/CMIP3 experiments. Earth Syst. Dyn., 4, 199-217, doi:10.5194/esd-4-199-2013.

, and J. Böhner, 2014: Seasonality of the hydrological cycle in major South and Southeast Asian river basins as simulated by PCMDI/CMIP3 experiments. Earth Syst. Dyn., 5, 67-87, doi:10.5194/esd-5-67-2014.

, S. Pascale, V. Lucarini, and J. Böhner, 2016: Seasonal cycle of precipitation over major river basins in South and Southeast Asia: A review of the CMIP5 climate models data for present climate and future climate projections. Atmos. Res., 180, 4263, doi:10.1016/j.atmosres.2016.05.008.

Henson, S. A., C. Beaulieu, and R. Lampitt, 2016: Observing climate change trends in ocean biogeochemistry: When and where. Global Change Biol., 22, 1561-1571, doi:10.1111/ gcb.13152.

Higuchi, K., Y. Ageta, T. Yasunari, and J. Inoue, 1982: Characteristics of precipitation during the monsoon season in highmountain areas of the Nepal Himalaya. IAHS Publ., 138, 21-30.

Hingray, B., and M. Saïd, 2014: Partitioning internal variability and model uncertainty components in a multimember multimodel ensemble of climate projections. J. Climate, 27, 6779-6798, doi:10.1175/JCLI-D-13-00629.1.

Immerzeel, W., 2008: Historical trends and future predictions of climate variability in the Brahmaputra basin. Int. J. Climatol., 28, 243-254, doi:10.1002/joc. 1528.

IPCC, 2001: Climate Change 2001: The Scientific Basis. Cambridge University Press, $881 \mathrm{pp}$.

Jain, S. K., and V. Kumar, 2012: Trend analysis of rainfall and temperature data for India. Curr. Sci., 102, 37-49.

,$- \ldots$, and M. Saharia, 2013: Analysis of rainfall and temperature trends in northeast India. Int. J. Climatol., 33, 968978, doi:10.1002/joc.3483.

Joetzjer, E., H. Douville, C. Delire, and P. Ciais, 2013: Presentday and future Amazonian precipitation in global climate 
models: CMIP5 versus CMIP3. Climate Dyn., 41, 29212936, doi:10.1007/s00382-012-1644-1.

Jourdain, N. C., A. Sen Gupta, A. S. Taschetto, C. C. Ummenhofer, A. F. Moise, and K. Ashok, 2013: The Indo-Australian monsoon and its relationship to ENSO and IOD in reanalysis data and the CMIP3/CMIP5 simulations. Climate Dyn., 41, 3073 3102, doi:10.1007/s00382-013-1676-1.

Kansakar, S. R., D. M. Hannah, J. Gerrard, and G. Rees, 2004: Spatial pattern in the precipitation regime of Nepal. Int. J. Climatol., 24, 1645-1659, doi:10.1002/joc.1098.

Kendall, M. G., 1957: Rank correlation methods. Biometrika, 44, 298, doi:10.2307/2333282.

Khan, A. R., 2001: Searching evidence for climatic change: Analysis of hydro-meteorological time series in the Upper Indus Basin. International Water Management Institute Rep. IWMI Working Paper 23, 31 pp., doi:10.3910/2009.152.

Kripalani, R. H., A. Kulkarni, and S. S. Sabade, 2003: Western Himalayan snow cover and Indian monsoon rainfall: A reexamination with INSAT and NCEP/NCAR data. Theor. Appl. Climatol., 74, 1-18, doi:10.1007/s00704-002-0699-z.

_ J. H. Oh, A. Kulkarni, S. S. Sabade, and H. S. Chaudhari, 2007: South Asian summer monsoon precipitation variability: Coupled climate model simulations and projections under IPCC AR4. Theor. Appl. Climatol., 90, 133-159, doi:10.1007/ s00704-006-0282-0.

Kumar, N., and A. K. Jaswal, 2016: Historical temporal variation in precipitation over western Himalayan region: 1857-2006. J. Mt. Sci., 13, 672-681, doi:10.1007/s11629-014-3194-y.

Kusunoki, S., and O. Arakawa, 2015: Are CMIP5 models better than CMIP3 models in simulating precipitation over East Asia? J. Climate, 28, 5601-5621, doi:10.1175/JCLI-D-14-00585.1.

Lafaysse, M., B. Hingray, A. Mezghani, J. Gailhard, and L. Terray, 2014: Internal variability and model uncertainty components in future hydrometeorological projections: The Alpine Durance basin. Water Resour. Res., 50, 3317-3341, doi:10.1002/ 2013 WR014897.

Lang, T. J., and A. P. Barros, 2004: Winter storms in the central Himalayas. J. Meteor. Soc. Japan, 82, 829-844, doi:10.2151/ jmsj.2004.829.

Lee, J. Y., and Coauthors, 2010: How are seasonal prediction skills related to models' performance on mean state and annual cycle? Climate Dyn., 35, 267-283, doi:10.1007/s00382-010-0857-4.

Mann, H. B., 1945: Nonparametric tests against trend. Econometrica, 13, 245, doi:10.2307/1907187.

Maraun, D., 2013: When will trends in European mean and heavy daily precipitation emerge? Environ. Res. Lett., 8, 014004, doi:10.1088/1748-9326/8/1/014004.

Meher, J. K., L. Das, and J. Akhter, 2014: Future rainfall change scenarios simulated through AR4 and AR5 GCMs over the Western Himalayan Region. J. Agrometeor., 16 (Special Issue I), 53-58.

—,- , and V. J. Singh, 2016: Analysis of trends in monsoon rainfall and its influence on productivity of Kharif rice: A district wide latest update. Crop Productivity and Plant Disease Management, A. Chauhan, P. K. Bharti, and D. Sadana, Eds., Discovery Publishing House, 60-77.

Mehrotra, R., A. Sharma, D. N. Kumar, and T. Reshmidevi, 2013: Assessing future rainfall projections using multiple GCMs and a multi-site stochastic downscaling model. J. Hydrol., 488, 84-100, doi:10.1016/j.jhydrol.2013.02.046.

Miao, C., Q. Duan, L. Yang, and A. G. L. Borthwick, 2012: On the applicability of temperature and precipitation data from CMIP3 for China. PLoS One, 7, doi:10.1371/journal.pone.0044659.
Nautiyal, J. C., and P. S. Babor, 1985: Forestry in the Himalayas: How to avert an environmental disaster. Interdiscip. Sci. Rev., 10, 27-41, doi:10.1179/isr.1985.10.1.27.

Negi, G. C. S., P. K. Samal, J. C. Kuniyal, B. P. Kothyari, R. K. Sharma, and P. P. Dhyani, 2012: Impact of climate change on the western Himalayan mountain ecosystems: An overview. Trop. Ecol., 53, 345-356.

Notz, D., 2015: How well must climate models agree with observations? Philos. Trans. Roy. Soc. London, 373A, 20140164, doi:10.1098/rsta.2014.0164.

Pai, D. S., L. Sridhar, M. Rajeevan, O. P. Sreejith, N. S. Satbhai, and B. Mukhopadhyay, 2014: Development of a new high spatial resolution $\left(0.25^{\circ} \times 0.25^{\circ}\right)$ long period (1901-2010) daily gridded rainfall data set over India and its comparison with existing data sets over the region. MAUSAM, 65, 1-18.

Pal, J. S., and Coauthors, 2007: Regional climate modeling for the developing world: The ICTP RegCM3 and RegCNET. Bull. Amer. Meteor. Soc., 88, 1395-1409, doi:10.1175/BAMS-88-9-1395.

Palazzi, E., J. V. Hardenberg, and A. Provenzale, 2013: Precipitation in the Hindu-Kush Karakoram Himalaya: Observations and future scenarios. J. Geophys. Res. Atmos., 118 85-100, doi:10.1029/2012JD018697.

,$- \ldots$, S. Terzago, and A. Provenzale, 2015: Precipitation in the Karakoram-Himalaya: A CMIP5 view. Climate Dyn., $\mathbf{4 5}$, 21-45, doi:10.1007/s00382-014-2341-z.

Palutikof, J. P., J. A. Winkler, C. M. Goodess, and J. A. Andresen, 1997: The simulation of daily temperature time series from GCM output. Part I: Comparison of model data with observations. J. Climate, 10, 2497-2513, doi:10.1175/1520-0442(1997)010<2497: TSODTT>2.0.CO;2.

Panday, P. K., J. Thibeault, and K. E. Frey, 2015: Changing temperature and precipitation extremes in the Hindu Kush-Himalayan region: An analysis of CMIP3 and CMIP5 simulations and projections. Int. J. Climatol., 35, 3058-3077, doi:10.1002/joc.4192.

Panthi, J., and Coauthors, 2015: Spatial and temporal variability of rainfall in the Gandaki River basin of Nepal Himalaya. Climate, 3, 210-226, doi:10.3390/cli3010210.

Pervez, M. S., and G. M. Henebry, 2014: Projections of the GangesBrahmaputra precipitation-Downscaled from GCM predictors. J. Hydrol., 517, 120-134, doi:10.1016/j.jhydrol.2014.05.016.

R Core Team, 2014: R: A Language and Environment for Statistical Computing. R Core Team R Foundation for Statistical Computing, Vienna, Austria.

Raju, K., and D. N. Kumar, 2014: Ranking of global climate models for India using multicriterion analysis. Climate Res., 60, 103117, doi:10.3354/cr01222.

— using TOPSIS. J. Water Climate Change, 6, 288-299, doi:10.2166/ wcc.2014.074.

Ramanathan, V., and Coauthors, 2005: Atmospheric brown clouds: Impacts on South Asian climate and hydrological cycle. Proc. Natl. Acad. Sci. USA, 102, 5326-5333, doi:10.1073/ pnas.0500656102.

Ramesh, K. V., and P. Goswami, 2014: Assessing reliability of regional climate projections: The case of Indian monsoon. Sci. Rep., 4, 4071, doi:10.1038/srep04071.

Ray, M., N. Doshi, N. Alag, and R. Sreedhar, 2011: Climate vulnerability in north western Himalayas: A contribution to the ongoing nation-wide climate studies. Environics Trust Indian Network on Ethics and Climate Change Rep., 50 pp.

Saha, A., S. Ghosh, A. S. Sahana, and E. P. Rao, 2014: Failure of CMIP5 climate models in simulating post-1950 decreasing 
trend of Indian monsoon. Geophys. Res. Lett., 41, 7323-7330, doi:10.1002/2014GL061573.

Salzmann, M., H. Weser, and R. Cherian, 2014: Robust response of Asian summer monsoon to anthropogenic aerosols in CMIP5 models. J. Geophys. Res. Atmos., 119, 11321-11337, doi:10.1002/ 2014JD021783.

Sanap, S. D., and G. Pandithurai, 2015: The effect of absorbing aerosols on Indian monsoon circulation and rainfall: A review. Atmos. Res., 164-165, 318-327, doi:10.1016/j.atmosres.2015.06.002.

Schaller, N., I. Mahlstein, J. Cermak, and R. Knutti, 2011: Analyzing precipitation projections: A comparison of different approaches to climate model evaluation. J. Geophys. Res., 116, D10118, doi:10.1029/2010JD014963.

Schönwiese, C.-D., and J. Rapp, 1997: Climate Trend Atlas of Europe Based on Observations 1891-1990. Springer, 228 pp., doi:10.1007/978-94-015-8818-8.

Sen, P. K., 1968: Estimates of the regression coefficient based on Kendall's tau. J. Amer. Stat. Assoc., 63, 1379-1389, doi:10.1080/ 01621459.1968.10480934.

Shashikanth, K., K. Salvi, S. Ghosh, and K. Rajendran, 2014: Do CMIP5 simulations of Indian summer monsoon rainfall differ from those of CMIP3? Atmos. Sci. Lett., 15, 79-85, doi:10.1002/ asl2.466.

Shekhar, M., H. Chand, S. Kumar, K. Srinivasan, and A. Ganju, 2010: Climate-change studies in the western Himalaya. Ann. Glaciol., 51, 105-112, doi:10.3189/172756410791386508.

Shrestha, A. B., and L. P. Devkota, 2010: Climate change in the eastern Himalayas: Observed trends and model projections; climate change impact and vulnerability in the eastern Himalayas. ICIMOD Tech. Rep. 1, 20 pp.

— C. P. Wake, J. E. Dibb, and P. A. Mayewski, 2000: Precipitation fluctuations in the Nepal Himalaya and its vicinity and relationship with some large scale climatological parameters. Int. J. Climatol., 20, 317-327, doi:10.1002/ (SICI)1097-0088(20000315)20:3<317::AID-JOC476>3.0.CO;2-G.

Singh, J., R. R. Yadav, and M. Wilmking, 2009: A 694-year tree-ring based rainfall reconstruction from Himachal Pradesh, India. Climate Dyn., 33, 1149-1158, doi:10.1007/s00382-009-0528-5.

Singh, P., and N. Kumar, 1997: Effect of orography on precipitation in the western Himalayan region. J. Hydrol., 199, 183-206, doi:10.1016/S0022-1694(96)03222-2.

_, K. S. Ramasastri, and N. Kumar, 1995: Topographical influence on precipitation distribution in different ranges of western Himalayas. Hydrol. Res., 26, 259-284.

Singh, R. B., and S. Mal, 2014: Trends and variability of monsoon and other rainfall seasons in western Himalaya, India. Atmos. Sci. Lett., 15, 218-226, doi:10.1002/asl2.494.

Singh, V., and M. K. Goyal, 2016: Analysis and trends of precipitation lapse rate and extreme indices over north Sikkim eastern
Himalayas under CMIP5 ESM-2M RCPs experiments. Atmos. Res., 167, 34-60, doi:10.1016/j.atmosres.2015.07.005.

Smith, I. N., and F. H. S. Chiew, 2009: Document and assess methods for generating inputs to hydrological models and extend delivery of projections across Victoria. South East Australian Climate Initiative Final Rep. 2.2.5P, 18 pp. [Available online at http://www.seaci.org/publications/ documents/SEACI-1\%20Reports/S1_FR225P.pdf.]

, and E. Chandler, 2010: Refining rainfall projections for the Murray Darling Basin of south-east Australia-The effect of sampling model results based on performance. Climatic Change, 102, 377-393, doi:10.1007/s10584-009-9757-1.

Song, F., and T. Zhou, 2014: Interannual variability of East Asian summer monsoon simulated by CMIP3 and CMIP5 AGCMs: Skill dependence on Indian Ocean-western Pacific anticyclone teleconnection. J. Climate, 27, 1679-1697, doi:10.1175/ JCLI-D-13-00248.1.

Sperber, K. R., H. Annamalai, I. S. Kang, A. Kitoh, A. Moise, A. Turner, B. Wang, and T. Zhou, 2013: The Asian summer monsoon: An intercomparison of CMIP5 vs. CMIP3 simulations of the late 20th century. Climate Dyn., 41, 2711-2744, doi:10.1007/s00382-012-1607-6.

Srinivasan, G., M. Hulme, and C. G. Jones, 1995: An evaluation of the spatial and interannual variability of tropical precipitation as simulated by GCMs. Geophys. Res. Lett., 22, 2139-2142, doi:10.1029/95GL01443.

Stainforth, D., M. Allen, E. Tredger, and L. Smith, 2007: Confidence, uncertainty and decision-support relevance in climate predictions. Philos. Trans. Roy. Soc. London, 365A, 21452161, doi:10.1098/rsta.2007.2074.

Su, F., X. Duan, D. Chen, Z. Hao, and L. Cuo, 2013: Evaluation of the global climate models in the CMIP5 over the Tibetan Plateau. J. Climate, 26, 3187-3208, doi:10.1175/JCLI-D-12-00321.1.

Suppiah, R., K. J. Hennessy, P. H. Whetton, K. McInnes, I. Macadam, J. Bathols, J. Ricketts, and C. M. Page, 2007: Australian climate change projections derived from simulations performed for the IPCC 4th Assessment Report. Aust. Meteor. Mag., 56, 131-152.

Taylor, K. E., R. J. Stouffer, and G. A. Meehl, 2012: An overview of CMIP5 and the experiment design. Bull. Amer. Meteor. Soc., 93, 485-498, doi:10.1175/BAMS-D-11-00094.1.

Tiwari, P. R., S. C. Kar, U. C. Mohanty, S. Kumari, P. Sinha, A. Nair, and S. Dey, 2014: Skill of precipitation prediction with GCMs over north India during winter season. Int. J. Climatol., 34, 3440-3455, doi:10.1002/joc.3921.

Wilby, R., L. Hay, and G. Leavesley, 1999: A comparison of downscaled and raw GCM output: Implications for climate change scenarios in the San Juan River basin, Colorado. J. Hydrol., 225, 67-91, doi:10.1016/S0022-1694(99)00136-5. 